\title{
A broadly applicable approach to $T$ cell epitope identification: Application to improving tumor associated epitopes and identifying epitopes in complex pathogens
}

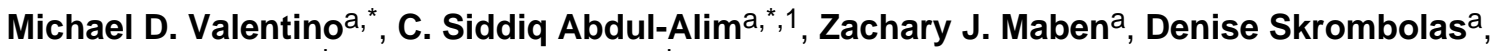 \\ Lucinda L. Hensley ${ }^{b}$, Thomas H. Kawula ${ }^{b}$, Michelle Dziejman ${ }^{a}$, Edith M. Lord ${ }^{a}$, Jeffrey A. \\ Frelinger ${ }^{b, c}$, and John G. Frelinger ${ }^{a}$ \\ aDepartment of Microbiology and Immunology, University of Rochester School of Medicine and \\ Dentistry, Rochester, New York, 14642, USA \\ bDepartment of Microbiology and Immunology, University of North Carolina at Chapel Hill, Chapel \\ Hill, North Carolina, 27599, USA \\ 'Department of Immunobiology, University of Arizona, Tucson, Arizona, 85724, USA
}

\section{Abstract}

Epitopes are a hallmark of the antigen specific immune response. The identification and characterization of epitopes is essential for modern immunologic studies, from investigating cellular responses against tumors to understanding host/pathogen interactions especially in the case of bacteria with intracellular residence. Here, we have utilized a novel approach to identify $T$ cell epitopes exploiting the exquisite ability of particulate antigens, in the form of beads, to deliver exogenous antigen to both MHC class I and class II pathways for presentation to T cell hybridomas. In the current study, we coupled this functional assay with two distinct protein expression libraries to develop a methodology for the characterization of T cell epitopes. One set of expression libraries containing single amino acid substitutions in a defined epitope sequence was interrogated to identify epitopes with enhanced T cell stimulation for a MHC class I epitope. The second expression library is comprised of the majority of open reading frames from the intracellular pathogen and potential biowarfare agent, Francisella tularensis. By automating aspects of this technology, we have been able to functionally screen and identify novel $\mathrm{T}$ cell epitopes within $F$. tularensis. We have also expanded upon these studies to generate a novel expression vector that enables immunization of recombinant protein into mice, which has been utilized to facilitate T cell epitope discovery for proteins that are critically linked to Francisella pathogenicity. This methodology should be applicable to a variety of systems and other pathogens.

(C) 2011 Elsevier B.V. All rights reserved.

Correspondence: M. D. Valentino, Department of Microbiology and Immunology, University of Rochester School of Medicine and Dentistry, 601 Elmwood Avenue Box 672, Rochester, New York, 14642., michael_valentino@urmc.rochester.edu.

${ }^{1}$ Present address: Program in Immunology, Clinical Research Division, Fred Hutchinson Cancer Research Center, Seattle, Washington, 98109, USA

*These authors contributed equally to this work.

Publisher's Disclaimer: This is a PDF file of an unedited manuscript that has been accepted for publication. As a service to our customers we are providing this early version of the manuscript. The manuscript will undergo copyediting, typesetting, and review of the resulting proof before it is published in its final citable form. Please note that during the production process errors may be discovered which could affect the content, and all legal disclaimers that apply to the journal pertain. 


\section{Keywords}

T cell epitope discovery; protein expression library; altered peptide ligands; Prostate Specific

Antigen; Francisella tularensis; high-throughput screening

\section{Introduction}

The identification and characterization of $\mathrm{T}$ cell epitopes has become essential for modern immunologic studies. Once identified, $\mathrm{T}$ cell epitopes can be used to monitor $\mathrm{T}$ cell responses using ELI-spot analyses or by flow cytometry analyses employing intracellular cytokine staining or MHC tetramer analyses (Altman et al., 1996; Chapman et al., 2002; McGavern et al., 2002; Kern et al., 2005). These techniques allowed investigators to characterize antigen specific $\mathrm{T}$ cells arising in response to a variety of pathogens as well as in anti-tumor responses (Ogg et al., 1998; He et al., 1999; Lee et al., 1999; McSorley et al., 2002; Stetson et al., 2002). Furthermore, the epitopes themselves can also be used in developing vaccines aimed at enhancing T cell responses (Pogue et al., 1995; Abdel-Motal et al., 2001; Kessler and Melief, 2007; Depla et al., 2008; Gregory et al., 2009).

Due to their importance and utility in immunology, a variety of functional and biochemical approaches have been developed to identify peptide epitopes (Hunt et al., 1992; Anthony and Lehmann, 2003; Koelle, 2003; Lemmel and Stevanovic, 2003; Sospedra et al., 2003; Wang, 2003; Buus and Claesson, 2004; Gunawardana and Diamandis, 2007; Kessler and Melief, 2007; Richards et al., 2010). The identification of peptide epitopes coupled with the development of large scale MHC peptide binding assays, has led to the development of in silico peptide binding algorithms and epitopes database tools for predicting MHC class I and class II epitopes (Bian et al., 2003; Martin et al., 2003; Peters et al., 2005). As information about epitopes has become available, it has been used to enhance responses to defined epitopes by increasing their binding to their respective MHC molecules (Pogue et al., 1995; Overwijk et al., 1998; Katsara et al., 2008). Further, as sequence information has become available for pathogens, attempts have been made to identify potential $\mathrm{T}$ cell epitopes in these pathogenic organisms (Doolan et al., 2003a; Doolan et al., 2003b; Gregory et al., 2009; Moise et al., 2009; Walsh et al., 2009; Alexander et al., 2010). Importantly the increasing amount of available sequence information, coupled with the recent advances in molecular biology and genomics, has enabled the construction of extensive expression libraries of defined proteins. These libraries offer new opportunities for a variety of innovative studies including the definition and characterization of B cell and $\mathrm{T}$ cell epitopes (Davies et al., 2008; Eyles et al., 2008; Valentino and Frelinger, 2009).

In the current study, we report the development of a method to screen expression libraries to define and characterize $\mathrm{T}$ cell epitopes. We have previously developed an approach employing the highly efficient processing of solid phase antigen delivery using antigen coupled to beads in conjunction with a functional assay to identify $\mathrm{T}$ cell epitopes in specific proteins (Turner et al., 2001; Valentino et al., 2009). An important feature of this assay is the use of a functional readout employing a $\mathrm{T}$ cell hybridoma that has been generated from $\mathrm{T}$ cells arising during an immune reaction, validating the epitope a priori. We reasoned that this basic method could be coupled with expression libraries to develop a high-throughput screening methodology for the identification of T cell epitopes. As described in this work, we have used bacterial expression libraries and the functional $\mathrm{T}$ cell screen for two distinct applications to illustrate its general utility.

In the first approach, we have screened a panel of expression libraries to identify altered peptide ligands (APL) that affect T cell stimulation. APL are peptides having amino acid 
substitutions that result in either enhanced or attenuated $\mathrm{T}$ cell responses compared to the parental wild-type ligand sequence. Altered peptide ligands are of interest since they are being used in a variety of contexts, including studies on T cell signaling and differentiation, autoimmunity, immune responses to tumors and infectious agents, and are also being investigated for clinical use (Klenerman et al., 1995; Rivoltini et al., 1995; Wang et al., 1999; Bielekova and Martin, 2001; Fong et al., 2001; Kessels et al., 2001; Aruna et al., 2006; Tsukamoto et al., 2006; Uhlin et al., 2006; Yu et al., 2008; Sadegh-Nasseri et al., 2010; Dominguez et al., 2011). In order to identify potential APL, we employed random mutagenesis methods to generate expression libraries of mutated T cell epitopes that could then be functionally screened to identify those with super-agonist properties. This mutagenesis approach, coupled with a functional screen, should allow one to identify improved epitopes without prior knowledge of which substitutions might result in enhanced recognition by $\mathrm{T}$ cells. As proof of principle of this approach to identify altered peptide ligands (APL), we used a T cell hybridoma which recognizes a previously described MHC class I restricted epitope of Prostate Specific Antigen (PSA 188 - 197) called HL10 (Turner et al., 2001) to screen a collection of 10 expression libraries we have constructed encoding variants of this epitope.

In the second approach using expression libraries, we have taken advantage of the availability of annotated genomic DNA libraries of pathogens determined by whole genome sequencing. From an available Gateway donor clone library, we constructed a bacterial expression library consisting of nearly all the open reading frames of Francisella tularensis strain SchuS4 (http://www.beiresources.org, 2011; http://www.jvci.org, 2011), chosen because $\mathrm{T}$ cells are important effectors in the response to this facultative intracellular pathogen (Elkins et al., 2007; Cowley and Elkins, 2011). Here we illustrate the feasibility of using an ordered array of Francisella tularensis genes to produce a library of recombinant proteins that can be screened for $\mathrm{T}$ cell epitopes. We further extend these studies by generating a new expression vector so that selected genes could be expressed and used for immunization studies. We have used this vector to express several proteins found within the Francisella pathogenicity island, that were used to immunize mice, generate $\mathrm{T}$ cell hybridomas, and identify $\mathrm{T}$ cell epitopes within the intracellular growth locus encoded proteins IglC and IglB.

\section{Methods and Materials}

\subsection{Generation and screening of the HL10 mutant collection}

The APL expression libraries were generated using oligonucleotides to mutagenize a class I epitope (HL10) from the wild type PSA sequence to the altered epitopes. These oligonucleotides included several features. Oligonucleotides were randomized at specific sequential positions to introduce mutations into the PSA 188 - 197 epitope (HL10). An example sequence of the epitope region of an oligonucleotide used to generate one of the ten positional mutant libraries was as follows: NNN CCT CAG AAG GTG ACC AAG TTC ATG CTG TAG A where NNN denotes the randomized codon at position 1 (P1) with the remaining encoding wild type HL10 epitope sequence. In addition, sequence corresponding to a 5 amino acid linker from wild type PSA was included immediately upstream of the mutagenic region to facilitate natural processing and presentation. Finally, to faciliate cloning the oligonucleotides included sequences that generate KpnI and HindIII compatible ends after annealing. The oligonucleotides were annealed to complimentary strands, ligated into the expression vector pQE40 (Qiagen, Valencia, CA) via KpnI and HindIII restriction sites, and verified by sequencing (ACGT, Northbrook, IL). The HL10 mutants are expressed as the $\mathrm{COOH}$-terminal portion of a fusion protein along with $\left(5^{\prime}-3^{\prime}\right)$ a $6 \mathrm{x}$ Histidine tag $(6 \mathrm{x}$ His), Dihydrofolate reductase (DHFR), and a fragment of ovalbumin (OVA 255 - 345). The $6 \mathrm{x}$-His tag facilitates the purification of the recombinant protein, DHFR allows for stable 
protein expression, and the ovalbumin fragment contains a $\mathrm{H} 2 \mathrm{~K}^{\mathrm{b}}$ restricted CTL epitope which allowed us to confirm protein expression using a $\mathrm{T}$ cell hybrid that is specific for the ovalbumin fragment (data not shown).

Approximately ninety mutant clones were used to generate each positional library of HL10. Six wells were left available for in-plate controls for each experiment. Individual bacterial colonies containing single mutant constructs were used to inoculate $100 \mu \mathrm{l}$ Luria Broth in 96well plates and grown overnight at $37^{\circ} \mathrm{C}$. Each plate was duplicated to a 96-well plate containing $70 \%$ glycerol and frozen, which served as the master library. Protein expression in $E$. coli was induced using $1 \mathrm{mM}$ IPTG. The bacterial cells were harvested by centrifugation, lysed with $8 \mathrm{M}$ urea ( $\mathrm{pH}$ 7.0) for 2 hours at room temperature. Following an additional centrifugation, supernatants were isolated as clarified lysates. An aliquot of each lysate $(20 \mu \mathrm{l})$ was added to PBS $(80 \mu \mathrm{l})$ in 96 -well polycarbonate plates, and tosyl-activated beads (Invitrogen, Carlsbad, CA) at a concentration of $2 \times 10^{9}$ beads $/ \mathrm{ml}$ were added to the diluted lysates and incubated for 16 hours at $37^{\circ} \mathrm{C}$. The beads were washed and added to tissue culture treated 96-well flat bottom plates containing $1 \times 10^{5}$ cells of the antigen presenting cell line RAW 264.7 and $2 \times 10^{5}$ the HL10 specific T cell hybrid, PSA-HI (Turner et al., 2001). The assay proceeded overnight at $37^{\circ} \mathrm{C}$. Activation of PSA-HI hybridoma was detected using the $\beta$-galactosidase substrate $\mathrm{X}$-gal and enumerating blue cells (Turner et al., 2001; Valentino et al., 2009; Valentino et al., 2011).

\subsection{HL10 mutant library peptides and relative binding assay}

The HL10 related peptides were purchased either from Macromolecular Resources (Fort Collins, CO) or SynPep Corporation (Palo Alto, CA) and are as follows: HL10 W.T. (HPQKVTKFML), H1A (APQKVTKFML), H1S (SPQKVTKFML), T6P (HPQKVPKFML), T6S (HPQKVSKFML), K7R (HPQKVTRFML), M9N (HPQKVTKFNL). Synthetic peptide $(20-80 \mu \mathrm{M})$ was added to the top well of a tissue culture treated 96-well plate and titrated using four-fold dilutions in 5\% MAT/P media. Reactivity assay was conducted as described above and $\beta$-galactosidase expression was detected using a soluble substrate, CPRG in Z-buffer, and the color development was measured at $610 \mathrm{~nm}$.

Relative peptide binding to $\mathrm{H} 2 \mathrm{~L}^{\mathrm{d}}$ was assessed by measuring the ability to stabilize $\mathrm{L}^{\mathrm{d}}$ on the surface of T2- $\mathrm{L}^{\mathrm{d}}$ cells. The cell line $\mathrm{T} 2-\mathrm{L}^{\mathrm{d}}$ is defective in endogenous peptide processing and thus expresses low levels of unstable $\mathrm{H}_{2} \mathrm{~L}^{\mathrm{d}}$ on its surface (Anderson et al., 1993). The binding of peptide to this unstable molecule stabilizes its structure, allowing it to be detected using an anti-H2 $\mathrm{L}^{\mathrm{d}}$ antibody. Cells were pulsed with $100 \mu \mathrm{M}$ of the appropriate peptide at $25^{\circ} \mathrm{C}$ for 16 hours in serum-free media. The cells were blocked with $1 \%$ goat serum for 1 hour on ice. Cells were then stained with saturating anti-H2 $\mathrm{L}^{\mathrm{d}}$ antibody (clone 30-5-7S), which is sensitive to peptide binding, on ice for 2 hours. Cells were then stained with goatanti-mouse FITC antibody and analyzed by FACScan ${ }^{\circledR}$ (Becton Dickinson \& Co., Mountain View, CA). Peptide loading to $L^{d}$ resulted in a proportional increase in mean channel fluorescence of antibody staining. The results are reported as the ratio of mean channel fluorescence of mutant and control peptides divided by the mean channel fluorescence of HL10, after the subtraction of background staining from each.

\subsection{Generating the Francisella tularensis SchuS4 expression library}

The J. Craig Venter Institute Pathogen Functional Genomics Resource Center (PFGRC) has made available, an arrayed genomic library containing the majority of ORFs from $F$. tularensis SchuS4 in the pDONR221 vector (http://pfgrc.jcvi.org/index.php/gateway_clones.html, 2011). Briefly, the PFGRC utilized annotated sequence of $F$. tularensis SchuS4 to amplify 1645 open reading frames to include 
native start codons, remove stop codons, and include att sites that facilitate recombination into the Gateway pDONR 211 vector. The plasmids were subsequently individually introduced into E. coli strain DH10B-T1 and the resulting genomic library is comprised of 1645 clones that have been sequence validated and individually arrayed into nineteen 96 well microtiter plates. The expression library clones were generated by shuttling each $F$. tularensis gene encoded in the pDONR221 vector into the bacterial expression vector pBAD-DEST49 using the Gateway Cloning technology (Invitrogen, Carlsbad, CA) following manufacturers specifications as previously described (Valentino and Frelinger, 2009). Briefly, the expression vector pBAD-DEST49 creates a fusion protein containing the bacterial protein thioredoxin (THIO) fused in frame with an individual ORF from $F$. tularensis SchuS4 followed by V6 and 6x histidine (6x His) coding regions.

Production of expression library thioredoxin fusion protein was performed as previously described with minor modifications (Valentino and Frelinger, 2009). Recombinant proteins were isolated by lysing the bacterial pellets with $8 \mathrm{M}$ urea $(\mathrm{pH} 8)$ either with or without addition of Nonidet P-40 detergent as indicated in the figure legends and purified over $\mathrm{Ni}$ NTA column (Qiagen, Valencia, CA) in a high-throughput fashion using a BioRobot 3000 (Qiagen, Valencia, CA). Purified protein was coupled to tosylactivated M280 magnetic Dynabeads (Invitrogen, Carlsbad, CA) as described (Valentino et al., 2009; Valentino et al., 2011). To examine expression and purification procedures, an aliquot of each purified protein from all of the library expression plates $(20 \times 96$ well plates $)$ was blotted onto Hybond C membrane using a 96-well dot blot apparatus (Bio-Rad, Hercules, CA). The membrane was blocked with 5\% non-fat dry milk in TBS-Tween before probing with antithioredoxin antibody (1:5000) for 2 hours at room temperature. The membrane was then washed 3 times in TBS-Tween before addition of rabbit anti-mouse IgG (Jackson Immunoresearch, West Grove, PA) conjugated to HRP detection antibody at a 1:5000 dilution for 1 hour at room temperature, followed by washing and detection using the ECL+ chemiluminescent reagent (GE Healthcare Life Sciences, Piscataway, NJ).

\subsection{Generation of hybridomas used for screening the Francisella expression library}

$\mathrm{C} 57 \mathrm{BL} / 6\left(H 2^{b}\right)$ and BALB/c $\left(H 2^{d}\right)$ mice were purchased from the Jackson Laboratory (Bar Harbor, ME). The T cell fusion partner BWZ.36/CD8 ${ }^{+}$, which can be used to make MHC class II and class I restricted hybridomas, was kindly provided by Dr. Nilabh Shastri and maintained as previously described (Sanderson and Shastri, 1994). The Tul4 specific hybridoma FT13 1E4B4 was previously characterized by our lab (Valentino et al., 2009). F. tularensis Live Vaccine Strain (LVS) was obtained from the CDC in Atlanta, GA.

T cell hybrids that were Francisella specific were produced in two ways as described previously (Valentino et al., 2009). Briefly, to generate hybridomas from a natural infection, $\mathrm{C} 57 \mathrm{BL} / 6$ or BALB/c mice were inoculated intradermally at the base of the tail with $1 \times 10^{5}$ viable $F$. tularensis LVS and allowed to rest for 3 weeks to resolve the infection before harvesting splenocytes (Cowley and Elkins, 2003). For the hybridomas generated with recombinant protein immunization, $\mathrm{C} 57 \mathrm{BL} / 6$ or BALB/c mice were injected in the footpad with approximately $50 \mu \mathrm{g}$ of recombinant proteins emulsified in complete Freund's adjuvant, rested for 3 weeks, and were then boosted once with recombinant proteins emulsified in incomplete Freund's adjuvant before harvesting draining popliteal lymph node seven days later. Following several rounds of in vitro restimulation, the T cell blasts from either natural infection or recombinant immunization were fused with the BWZ.36/CD8 ${ }^{+}$fusion partner containing lacZ driven by the Interleukin-2 promotor element as described (Sanderson and Shastri, 1994; Turner et al., 2001). Fusions from both approaches were grown in HAT selection media until clones could be evaluated for activity, measured by using a betagalactosidase substrate as previously described (Valentino et al., 2011). While the recovery of antigen specific hybridomas was very variable, likely depending on the immunization 
efficacy as well as the restimulation procedure, a typical fusion might yield approximately $100-150$ growing wells, of which $20-50 \%$ could be triggered with anti-CD3. Of those hybridomas, 1-20\% appeared to be Francisella specific and these were almost all class II restricted.

\subsection{Antigen screening of SchuS4 library}

The antigen screening assay was adapted from the $\mathrm{T}$ cell antigen discovery (T-CAD) assay (Turner et al., 2001). Screening assays were performed by incubating $2 \times 10^{5}$ hybridomas with $1 \times 10^{5}$ irradiated spleen cells as APC in $200 \mu \mathrm{l}$ total volume per well in a 96 well tissue culture plate. Syngeneic spleen cells were harvested from naïve wild type C57BL/6 or $\mathrm{BALB} / \mathrm{c}$ mice. All recombinant proteins used were isolated from bacterial lysates, conjugated to tosyl-activated beads in either 96 well plates for throughput library screening or $1.5 \mathrm{ml}$ tubes for deletion mapping as described above, and used at $2 \times 10^{6}$ beads per well. The coupling procedure was carried out in $1.2 \mathrm{ml}$ deep 96 well plates to maintain the highthroughput and arrayed feature of the library. Assays were also performed in the presence of synthesized peptides listed below at $10 \mu \mathrm{g}$ per peptide and Francisella lysates at $20 \mu \mathrm{g}$ per well. Additional positive controls for hybridoma viability and functionality that were included in each screening assay but not shown in figures were Francisella extracts, produced by killing $F$. tularensis LVS or SchuS4 in 70\% ethanol (Woolard et al., 2007), and plate bound anti-CD3 antibody (clone 500A2) (BD Pharmingen, San Jose, CA). After 18-24 hour incubation at $37^{\circ} \mathrm{C}$, cultures were developed using the beta-galactosidase assay as described previously (Sanderson and Shastri, 1994; Valentino et al., 2011). For data analysis, wells with low numbers of activated $(<1000$ blue cells) the entire well was visually counted. In wells with high numbers ( $>1000$ blue cells) four representative fields of view were counted, averaged, and multiplied by the number of fields per well (Valentino et al., 2009).

\subsection{Deletion construct mapping and Francisella tularensis peptides}

Deletion constructs were generated and mapping experiments conducted basically as described previously (Valentino et al., 2009; Valentino et al., 2011). Briefly, nested carboxy-terminal deletion constructs were generated in either the pQE40 or pBAD-DEST49 vector. Production of all fusion proteins was performed in Escherichia coli strain M15 as described by manufacturers specifications (Qiagen, Valencia, CA). Recombinant proteins were isolated from bacterial lysates by Ni-NTA column purification and coupled to tosylactivated Dynabeads (Invitrogen, Carlsbad, CA). Deletion construct production and characterization was confirmed by SDS-PAGE techniques and Coomassie Blue staining as described previously (data not shown) (Turner et al., 2001).

The refined regions shown by deletion protein mapping to contain an epitope were analyzed with several peptide prediction algorithms: Rankpep,

http://imed.med.ucm.es/Tools/rankpep.html, 2011; NetMHCII 2.0, http://www.cbs.dtu.dk/services/NetMHCII-2.0/, 2011; and IEDB Analysis Resource http://tools.immuneepitope.org/analyze/html/mhc_II_binding.html, 2011. F. tularensis peptides were synthesized by SynBioSci (Livermore, CA) and are as follows: L3 1-21 (MSLGLVGRKCGMTRIFTEDGV), L3 721 (GRKCGMTRIFTEDGV), L3 7 (C10S) - 21 (GRKSGMTRIFTEDGV), IglB 472 - 486 (IPGKPGWYSCKINVI), IglB 475 - 489 (KPGWYSCKINVIPHI), IglB 475 - 486 (KPGWYSCKINVI), GroEL 441 - 455 (ALLRKAIEAPLRQIV), IglC 56- 70 (GEDVTKADSATAAS), IglC 60 - 73 (TKADSATAASVIR), IglC 127 - 143 (QEYKTDEAWGIMIDLSN), IglC 131-147 (DEAWGIMIDLSNLELY), IglC 142 - 157 (SNLELYPISAKAFSISI). The Tul4 86 - 99 (RLQWQAPEGSKCHD) peptide derived from $F$. tularensis was also synthesized by SynBioSci (Livermore, CA) (Valentino et al., 2009). OVA 323 - 339 (pOVAII) peptide 
(ISQAVHAAHAEINEAGR) served as irrelevant peptide negative control and was synthesized by Macro-Molecular Resources (University of Colorado, Ft. Collins, CO). The B-lymphoblastoid cell line M12 parental expressing I- $\mathrm{E}^{\mathrm{d}}$ and $\mathrm{I}-\mathrm{A}^{\mathrm{d}}$ and $\mathrm{M} 12$ lines expressing only I-E $\mathrm{E}^{\mathrm{d}}$ (M12.A) or I-A ${ }^{\mathrm{d}}$ (M12.B) were used to ascertain which restriction element displays the L3 peptide (Qiagen, Valencia, CA).

\subsection{Generation of a novel Gateway compatible vector}

The Gateway compatible pQE40-DEST expression vector was generated by blunt end cloning the Gateway Vector Conversion cassette (Invitrogen, Carlsbad, CA), containing chloramphenicol resistance and $c c d B$ gene flanked by attR recombination sites, into the SmaI restriction site within the multiple cloning site (MCS) of the pQE40 vector. The ligation product was transformed into One Shot ccdB survival cells (Invitrogen, Carlsbad, CA) and transformants were selected on chloramphenicol/ampicillin plates. The pQE40DEST vector was validated based upon sequence analysis and verifying correct functionality in the Gateway cloning system as described by the manufacturer (Invitrogen, Carlsbad, CA).

\section{Results \& Discussion}

\subsection{Construction and analysis of the mutant libraries}

We sought to develop an approach that could facilitate throughput processing of large numbers of clones, in an effort to discover altered peptides of a MHC class I restricted epitope of Prostate Specific Antigen (PSA), called HL10, that were better than the initial wild type epitope in stimulating a T cell hybridoma. A modified version of the pQE40 vector construct was used to express the altered forms of HL10 epitope. As illustrated in Figure 1A, the HL10 epitope was expressed in the context of a fusion protein containing a 6x-Histidine tag at the amino-terminus, dihydrofolate reductase (DHFR) to facilitate stable expression in E. coli., a fragment of the protein ovalbumin (OVA 255-354), which allows for additional control experiments, and the HL10 epitope preceded by 5 amino acids that naturally precede HL10 in PSA, to allow for proper processing and loading of HL10 onto class I MHC molecules.

To introduce mutations into the plasmid encoding HL10, we utilized oligonucleotides that were randomized at a given codon (Fig. 1B). In this technique we sequentially mutagenized each codon individually by a saturation mutagenesis technique, and since the epitope contained 10 amino acids we generated 10 libraries, one for each amino acid. As shown in Figure 1C, the mutant constructs from each library were then cloned en mass into the pQE40 expression vector and transformed into E.coli. as described in the Materials and Methods section 2.1. Positional mutant HL10 libraries were generated by picking approximately 90 clones to a 96-well plate for each of the 10 amino acid positions. These 10 individual positional mutant libraries (P1-P10) are referred to as the HL10 mutant collection. The library was analyzed for randomness by isolating 72 clones from the position 1 (P1) library and sequencing the epitopes encoded by the plasmid (data not shown). From this number of clones, we identified 15 different amino acid substitutions as well as 1 stop codon at position 1. As expected, based on the genetic code, some amino acids are more commonly identified than others. There may also be some bias over the expected value toward mutations with more GC content, perhaps because of better base pairing. Nevertheless, this approach clearly generates a large bank of suitable mutants for screening. Upon validation that the individual positional libraries could contain assorted mutants, protein expression for the entire HL10 mutant collection was induced and crude lysates from each mutant clone individually coupled to tosyl activated paramagnetic beads to generate a solid phase antigen to be used in a T cell hybridoma functional assay, as described in Materials and Methods section 2.1 (Figure 1C). SDS polyacrylamide gel electrophoresis followed by Coomassie staining 
indicated that as expected, similar levels of protein were expressed since the mutant epitopes were different from one another by only 1 amino acid substitution (data not shown).

By using the random mutagenesis methods discussed above and a functional screen, we speculated that we could identify improved APL without prior knowledge or preconceived ideas as to which substitutions might result in enhanced recognition by T cells. The functional screen was conducted by administering the expressed mutant APLs coupled to beads to APCs for processing and presentation to the PSA-HI hybridoma, which recognizes the HL10 epitope in conjunction with the $\mathrm{L}^{\mathrm{d}}$ class I molecule. Hybridoma activation was scored by enumerating the number of $\beta$-galactosidase expressing (blue) $\mathrm{T}$ cell hybrids in each well after developing with X-gal substrate, as done previously (Figure 2). Several clones resulted in dramatically enhanced stimulation as illustrated by the increased number of activated hybridomas, while most of the clones in the library elicited little or no increase in the activation of the hybridoma compared to wild type peptide. All of the clones that appeared to increase the activation of the PSA-HI hybridoma were picked from the master library, re-screened functionally (data not shown), and the plasmid DNA encoding the putative mutant epitopes were sequenced to identify amino acid substitutions (see Figure 2). Several conclusions emerge from these studies. First, there were wide ranges in the degree of improvement of recognition ranging from 2 fold to more than 70 fold as measured by activation of the hybridoma. Second, the vast majority of the clones retested positive, and there were only 2 clones that did not retest positive in a subsequent re-screen. In one case, DNA sequencing revealed that the putative mutant in the position 3 library was a false positive, as it encoded the wild type amino acid (see Figure 2 P3 Q(WT)). In another case, the putative mutant clone in position 4 library $(\mathrm{P} 4 \mathrm{~K} \rightarrow \mathrm{V})$, while indeed encoding a substitution, failed to result in significant increase above the wild type construct when retested. Third, the assay was surprisingly quantitative and consistent in that different clones containing the same amino acid substitution in a given library (compare all the $\mathrm{P}$ substitutions in Figure 2 P6), led to similar increases in PSA-HI hybridoma activation. For example, the best activators in the position 1 library encoded alanine substitutions, while the serine mutants were somewhat less stimulatory. Similarly, in the position 6 library, the serine substitutions were more stimulatory that the proline substitutions (Figure 2). This was consistently found even in independent mutations encoded by different codons. Taken together, these results demonstrate that screening large numbers of clones is both feasible and highly reproducible using the approach described above.

\subsection{Analyses using synthetic peptides}

Data from the screen strongly suggested that a number of the altered peptides result in enhanced $\mathrm{T}$ cell recognition. However, to obtain more quantitative data and to rigorously examine this issue, we tested these mutants using synthetic peptides corresponding to each substitution (Figure 3). This allowed us to compare directly the peptides at varying concentrations and to determine quantitatively how the altered peptides compared to wild type HL10 peptide in their ability to activate the PSA-HI hybridoma. When tested, all of the mutant peptides resulted in significantly better activation of the PSA-HI hybridoma than the wild type peptide on a molar basis, with the exception of the HL10 mutant F8G which was included as a negative control peptide in these studies (Figure 3). The strength of the synthetic peptides generally followed the same pattern as seen in the initial screen using crude extracts. For example, the histidine to serine substitution at position 1 (H1S) was the least potent of the identified mutants, while the threonine to serine substitution at position 6 (T6S) was the most potent. Interestingly, the mutants are even more potent when tested using purified synthetic peptides than what might be expected from the initial screen. For example, serine substitution at position 6 yields an increase in activity of 10,000 fold as compared to the wild type peptide based on the concentration of peptide required to reach 
the half-maximal activation level of PSA-HI. These results demonstrate that this screen can identify enhanced altered peptides of a class I MHC restricted epitope.

\subsection{MHC binding ability of the enhanced APL}

We wanted to determine the nature of the enhanced APLs. We hypothesized that the APLs were likely to be one of two classes of substitutions: those that have a higher affinity for the class I MHC molecule or those that have higher affinity for the T cell receptor of PSA-HI. As a means of determining the relative ability of the peptides to bind to MHC molecules, we performed an experiment examining the ability of the peptides to stabilize $\mathrm{L}^{\mathrm{d}}$ molecules at the surface of the TAP-deficient mutant cell line T2- $\mathrm{L}^{\mathrm{d}}$. Because this cell line lacks a functional TAP transporter system necessary for loading peptides onto class I molecules, the cells bear low levels of class I molecules on their surface. However, these class I molecules can be stabilized by exogenous peptides, which results in increased expression that can be measured by flow cytometry using a monoclonal antibody specific for $\mathrm{L}^{\mathrm{d}}$. In these experiments, binding was calculated relative to wild type HL10 peptide and expressed as a ratio, with the level of stabilization of $L^{d}$ by HL10 being defined as 1. As shown in Figure 4, using this assay, the peptides H1A and H1S, could be characterized with enhanced binding, showing a 1.6 and 1.8 fold increase, respectively. Additional studies using a competition binding assay also indicated that the histidine to alanine mutation increased binding to the MHC (data not shown). This is consistent with prior studies using a different $\mathrm{H}_{2} \mathrm{~L}^{\mathrm{d}}$ binding peptide in which an alanine substitution at the first position resulted in better binding than the wild-type peptide (Slansky et al., 2000). Curation and analysis of peptide binding data has identified the preferred anchor residues for $\mathrm{H} 2 \mathrm{~L}^{\mathrm{d}}$ to be a proline at position 2 and either an asparagine, tryptophan, or tyrosine at position 9 (see Immune Epitope Database and Analysis Resource at http://www.immuneepitope.org, 2011; and (Vita et al., 2008; Vita et al., 2010)). Several interesting observations can be made when the binding motif of $\mathrm{H}_{2} \mathrm{~L}^{\mathrm{d}}$ is compared to the wild type HL10 epitope and the APLs identified by our screen. The wild type HL10 peptide contains a proline at the P2 position and no position 2 mutant APLs were identified, reinforcing that position 2 is indeed a major anchor. While the HL10 peptide contains a methionine residue at position 9, our mutant screen identified an APL (M9N) that exhibited in increased hybridoma reactivity that also exhibited decreased peptide binding. This is of interest because the substitution is from a tolerated (methionine) to a preferred (asparagine) residue in the $\mathrm{P} 9$ anchor, which might have been expected to increase binding stability. The peptides T6S and T6P were shown to stabilize H2L $\mathrm{L}^{\mathrm{d}}$ approximately the same as HL10 peptide, whereas the peptides K7R and M9N stabilize $\mathrm{H}_{2} \mathrm{~L}^{\mathrm{d}}$ less well than the wild type HL10 peptide. These results suggest that the screen can identify two classes of APLs, those that affect MHC binding (H1A and H1S peptides) and since the second class does not bind MHC as well, we would infer that the second class mutants affect the interaction of the peptide:MHC complex with the T cell receptor (T6S, T6P, K7R, and M9N peptides). Indeed, when these APLs (T6S, T6P, K7R) are compared to the published $\mathrm{H}_{2} \mathrm{~L}^{\mathrm{d}}$ motif, these residues are predicted to be found between anchor residues and thus potentially available for peptide:TCR interactions.

\subsection{Overview and characterization of a genomic library of F. tularensis SchuS4 ORFs}

The utility of the HL10 mutant collection for identifying novel altered peptide ligands led us to speculate that this approach could be modified and applied to the identification of novel antigen reactivities within pathogen genomes. We took advantage of a genomic library of Francisella tularensis to test the feasibility of utilizing a defined genomic array to identify novel targets of cellular immunity. The $F$. tularensis SchuS4 library encompasses the majority of open reading frames (ORF) within a set of approximately 1800 bacterial clones in a Gateway donor vector. For this work we used the bacterial expression vector pBADDEST49, which produces a fusion protein containing the bacterial protein thioredoxin fused 
to the Francisella ORF followed by V5 and 6x His tags (Figure 5A). The Francisella entry clone library was shifted individually into the pBAD-DEST49 expression vector and a random selection of clones from each recombined library plate was sampled for sequence verification for quality control purposes, as described in Materials and Methods section 2.3. The library of pBAD-DEST49 clones, constituting the expression library, was then used for protein production of antigens from $F$. tularensis strain SchuS4 (Valentino and Frelinger, 2009). Importantly, the library was acquired in a 96 well plate, arrayed format, which was maintained throughout the production and isolation of recombinant protein. Our initital analysis of crude lysates from the Francisella expression clones indicated that there was significant variability in the protein expression levels (data not shown), which are likely influenced by the characteristics of the particular Francisella ORF. This finding was in contrast to the HL10 mutant collection where the clones exhibited almost equivalent levels of protein expression amongst all the clones in the collection, likely due to each clone being identical except for a single amino acid substitution. However, we reasoned that purification of the Francisella proteins using the 6x His tag expressed on each protein could help mitigate this variability or at least generate sufficient material to be tested. The purification step was carried out in a high-throughput fashion aided by a semi-automated BioRobot 3000 to purify the proteins using Ni-NTA column in a 96 well plate format, as reviewed by our lab (Valentino and Frelinger, 2009).

To verify expression and purification, individual plates from the Francisella expression library were transferred onto nitrocellulose membranes using a 96 well dot blot apparatus and proteins detected by antibody directed against the thioredoxin fusion partner protein (see Figure 5A). Importantly, since the proteins were purified using the 6xHis tag located at the carboxyl-terminus and detected with anti-thioredoxin antibodies directed at the aminoterminus, these dot blots should detect full-length proteins. As seen in Figure 5B for a selection of plates, Ni-NTA purification was successful in isolating approximately $75 \%$ of recombinant proteins in our library. In general, the smaller ORFs (43-163 amino acids (aa)) were routinely expressed and purified efficiently, but interestingly, we observed a decrease in the efficiency of protein production and purification with increasing ORF size. We propose that this may reflect factors intrinsic to the larger ORFs, such as potential membrane localization or hydrophobicity properties. This line of reasoning led us to speculate whether or not the purification efficiency could be improved with the addition of detergent to the lysis buffer. As illustrated in Figure 5C, the purification efficiency for every size range of ORF could be improved by the simple addition of Nonidet P-40 (NP-40) detergent to the lysis buffer. These data indicated that approximately $85 \%$ of the Francisella expression library could be expressed and purified and was now available as a source of antigen for the $\mathrm{T}$ cell hybridoma functional screenings. While the studies presented here focus on identification of cellular reactivity, several recent studies have also indicated a role for antibodies directed against Francisella antigens (Baron et al., 2007; Kirimanjeswara et al., 2007; Kirimanjeswara et al., 2008; Rawool et al., 2008). The data shown in Figure 5 together with other evidence from our lab (Valentino et al., 2011) suggest that the dot blots could also be used to interrogate the Francisella expression library for antibody reactivities that may arise during infection or immunization.

\subsection{Identification of $T$ cell antigens within the F. tularensis SchuS4 expression library}

Employing an approach conceptually similar to that used to identify APLs, the purified recombinant-expressed Francisella proteins were individually coupled to tosyl-activated beads and screened against Francisella specific hybridomas in a T cell functional assay. This approach allowed for the screening of the majority of the F. tularensis strain SchuS4 proteome. In preparation for screening, we evaluated the approach using the hybridoma FT13 1E4B4, which was previously described to recognize the Francisella lipoprotein Tul4 
(Valentino et al., 2009) and serves as a positive control when screened with the library plate (designated plate KP) that contains its cognate protein Tul4 (also referred to as Lpn) (Figure $6 \mathrm{~A}$ ). As can be seen from Figure 6A, the FT13 1E4B4 is activated only by the single well of the 96 well plate that contains Tul4 protein (well H2), while all other wells show low reactivity as expected, serving as internal negative controls. The specificity and sensitivity of the $\mathrm{T}$ cell functional assay supported the concept that screening the expression library against hybridomas with unknown molecular reactivity would yield cellular reactive antigens. Indeed, through one of our screenings, the FT25 6D10 hybridoma, generated by infection with $F$. tularensis LVS, was found to be activated by the well $\mathrm{H} 11$ of library plate $\mathrm{KS}$, which encoded the 50S ribosomal subunit protein L3 (Figure 6B). To assess variability and re-validate the putative reactivity of the FT25 6D10 hybridoma towards L3 protein found during the screening (Figure 6A\&B), a 'criss-cross' experiment was conducted (Figure 6C). In this experiment a subset of five proteins from both plates KP and KS were re-arrayed in a 96 well plate to include replicates and were screened against each of the hybridomas. As expected, the Tul4 specific hybridoma FT13 1E4B4 was only activated by the wells containing Tul4 protein (0901) (Figure 6C top). Furthermore, the FT25 6D10 specificity for $\mathrm{L} 3$ protein was confirmed because only the wells producing the protein $\mathrm{L} 3$ (0128) activated the hybridoma with minimal variability between replicates (Figure 6C bottom). These experiments indicate that screening a proteome-wide expression library with a $\mathrm{T}$ cell functional assay is a feasible approach to identify cellular targets within a complex organism.

\subsection{Mapping and validation of the epitope recognized within L3}

Upon discovering cellular reactivity towards the L3 protein, it was also of interest to identify the minimum active peptide epitope that was specifically recognized by the hybridoma. Our laboratory has also used the $\mathrm{T}$ cell functional assay platform to successfully map the specific $\mathrm{T}$ cell molecular determinants in defined antigens (Turner et al., 2001; Valentino et al., 2009; Valentino et al., 2011). We have taken a similar approach to that described previously to map the epitope within L3 recognized by the FT25 6D10 hybridoma and used carboxyterminal deletion constructs of L3 expressed in the pQE40 vector (Figure 7A). In this approach, the loss of hybridoma reactivity indicates the recognized epitope is no longer present in the construct and thus is unable to activate the hybridoma. As shown in Figure 7B, FT25 6D10 hybridoma reactivity could be mapped to the first 35 amino acids of L3 (Figure 7B). Further deletion constructs within these amino acids identified residues $1-19$ as the minimal peptide necessary for hybridoma activation, with amino acids $1-22$ having the greatest stimulatory capacity (Figure 7C). Synthesized peptides containing residues 1 21 and $7-21$ of L3 were shown to be fully capable for eliciting FT25 6D10 activation (Figure 7D), indicating that these residues were indeed the epitope as presented complexed with the I-A ${ }^{\mathrm{d}}$ restriction element (Figure 7E). The presence of a cysteine residue was shown to have little effect on the stimulatory capability of the epitope, such that the altered peptide (L3 7-(C10S)-21) showed similar reactivity as the wild type peptide 7-21 (see Figure 7D).

The identification of a ribosomal protein subunit L3 is consistent with previously reported results that identified ribosomal $\mathrm{T}$ cell determinants in other pathogens, such as Trypanosoma cruzi (Mesri et al., 1990) and Leishmania major (Probst et al., 2001). Other studies have described the immunogenicity of ribosomal components and ribosome-based vaccines from various pathogens, such as Mycobacterium tuberculosis (Youmans and Youmans, 1964b; Youmans and Youmans, 1964a; Youmans and Youmans, 1970), Salmonella typhimurium (Venneman and Bigley, 1969; Johnson, 1972; Johnson, 1973; Eisenstein, 1975; Hoops et al., 1976; Misfeldt and Johnson, 1976; Misfeldt and Johnson, 1977; Eisenstein and Angerman, 1978; Misfeldt and Johnson, 1978; Misfeldt and Johnson, 1979; Angerman and Eisenstein, 1980; Kita and Kashiba, 1983; Kita et al., 1983a; Kita et 
al., 1983b), Francisella tularensis (Andron and Eigelsbach, 1975) and others (reviewed in (Gregory, 1986)). Our discovery of a T cell epitope within the Francisella ribosomal protein L3 is therefore in agreement with several of these studies and provides further evidence indicating that riboproteins can elicit cellular reactivity in the context of infection and vaccination (Gregory, 1986).

\subsection{Generation of a novel Gateway destination vector}

As described above, we have utilized a proteome-wide expression library to screen $F$. tularensis reactive hybridomas of unknown specificity to identify the antigen recognized by their cellular reactivity. To further extend the utility of this system and as a complementary approach we also sought to identify epitopes in a selection of specific antigens by recombinant protein immunization. The arrayed format of the expression library enables the selection of specific antigens for immunization. However, these proteins as expressed in the pBAD-DEST49 vector contain the bacterial protein thioredoxin, which makes this construct less desirable for immunization in mice, because of the potential for also generating thioredoxin specific hybridomas, which can complicate the screening process.

Given the efficiency and utility of the Gateway system for shifting and expressing the entire Francisella clone library, we were also interested in developing a Gateway vector that could be used in the same manner but would also be useful for producing protein that could be used for immunization in mice. We engineered a novel Gateway compatible vector, called pQE40-DEST, by inserting the Gateway cassette that contains the chloramphenicol resistance and $c c d B$ gene flanked by attR recombination sites into the pQE40 expression vector (Figure 8A). ORFs from an entry clone library can be shifted into this new destination vector in a fashion similar to that described above for pBAD-DEST49. However, the pQE40-DEST vector differs from the pBAD-DEST49 vector in several respects. The pQE40-DEST vector is IPTG inducible and produces a fusion protein containing a $6 x$ His tag followed by mouse dihydrofolate reductase (DHFR) fused in frame with the Francisella ORF (Figure 8B). The presence of DHFR affords stability and solubility to the fused ORF, while minimizing immunoreactivity when immunizing mice with recombinant protein, by virtue of the DHFR being a mouse protein.

As a proof of principle, we shifted and expressed a subset of the Francisella Pathogenicity Island (FPI) genes, the intracellular growth locus (igl) ABCD operon genes, and used the recombinant-expressed protein in immunization of mice. The genes encoded within the FPI, including the iglABCD operon, were of particular interest because studies have shown they are bacterial factors that are expressed in the intracellular environment (in particular, genes found within the iglABCD operon are among those most strongly upregulated) and are essential for phagosomal escape, intracellular replication, and the overall virulence of Francisella (Barker and Klose, 2007; Nano and Schmerk, 2007; Wehrly et al., 2009). The important roles of the iglABCD genes in bacterial pathogenicity subsequently make them interesting protein targets for the anti-Francisella immune response, since the bacteria would not be able to delete these genes without suffering a severe loss of fitness in vivo. Proteins from these constructs were therefore expressed, purified, and injected into mice to generate antigen specific $\mathrm{T}$ cells. Hybridomas generated by this approach were screened in functional assays against anti-CD3, the IglA, IglB, IglC, and IglD proteins individually coupled to tosylactivated beads, and an irrelevant protein control (Tul4) coupled to tosylactivated beads. Hybridomas that were activated by anti-CD3 and only one of the four Igl proteins, and did not react with Tul4 protein, were deemed as having the appropriate reactivity pattern. For these in vitro reactivity screenings, we could also take advantage of iglA, iglB, iglC, and iglD expressed using the pBAD-DEST49 vector, which contain thioredoxin in the fusion protein. Since the mice were not immunized with thioredoxin containing proteins, reactivity seen against these proteins during screening would indicate 
that the hybridoma specifically recognizes the Igl protein and not the DHFR region. Employing this approach, we were able to identify a panel of hybridomas that specifically recognized either IglB or IglC protein (data not shown).

As outlined above it was of considerable interest to also define the peptide epitopes recognized within IglB and IglC. Thus, the antigen specific hybridomas were then subjected to mapping experiments with deletion constructs to identify the antigenic region containing the epitope recognized by the hybridomas as thoroughly described above in the case of the protein L3 (see Figure 7). An illustration of the hybridoma reactivity patterns for IglC and IglB proteins are shown in Figure 8C-E. Hybridomas from C57BL/6 mice were shown to recognize two regions in $\mathrm{IglC}$, where as those identified from $\mathrm{BALB} / \mathrm{c}$ mice were found to recognize only one region in IglC. These experiments identifying the reactive regions that likely contained the epitopes guided the synthesis of peptides, which were subsequently validated by screening for hybridoma reactivity (Figure 9). As shown in Figure 9A, the one set of hybridomas (VE11 \& IID5) from C57BL/6 mice could be activated by the peptides containing residues 56-70 and 60-73, but not residues 65-80, indicating that the minimal epitope recognized by these hybridomas is most likely residues 60-70 of IglC. Another set of IglC-specific hybridomas (VB3 \& IVB7) from C57BL/6 mice that recognized a disparate region of IglC, were activated only by the peptide encoding residues 142-157 of IglC

(Figure 9A). Perhaps not surprisingly, while reactive to the same overall region within IglC as the hybridomas from C57BL/6 mice, the pair of hybridomas from BALB/c animals (IIIE6 \& IVD4) were activated by peptides that contained amino acids 127-143 and 131-147 of IglC and not by the residues 142-157 (see Figure 9B), indicating that BALB/c mice recognize a slightly different epitope peptide compared to those isolated from C57BL/6 mice, most likely due to potential differences in MHC binding between these two strains of mice. The IglB-specific hybridoma (VB10) from C57BL/6 mice was activated by all three peptides screened, likely due to the significant overlap in amino acid residues, with the peptide containing amino acids $475-489$ of IglB eliciting the strongest reactivity (Figure 9C). As summarized in Table 1, these studies identified one peptide epitope in IglB in C57BL/6 mice, three peptides containing two unique epitopes of IglC in C57BL/6 mice, and two peptides containing one unique epitope of IglC in BALB/c mice.

Importantly, additional experiments beyond the scope of this report may address the question of whether any of the IglB or IglC epitopes described here could potentially be protective. In a study by Jia et al, immunization with Listeria monocytogenes recombinantly expressing IglC was shown to afford significant protection in BALB/c mice against lethal aerosol challenge with both low and high virulence strains of Francisella tularensis, implicating a potential protective role for the protein IglC, however the $\mathrm{T}$ cell epitopes recognized during infection were not determined (Jia et al., 2009). Intriguingly, we found that immunization with recombinant IglB resulted in T cell reactivity against an epitope that is identical to one that occurs naturally during infection with $F$. tularensis LVS (Valentino et al., 2011).

\section{Conclusions}

In this work we have developed a functional assay to screen particulate antigens in the form of protein conjugated to beads. Because it is a functional screen, a key element of the process is the antigen-specific T cell hybridoma. Here, aided by genomic sequence data and a high throughput approach, we have used this method to screen two distinct bacterial expression libraries to demonstrate its versatility. The HL10 mutant epitope collection, made up of 10 individual positional libraries, enabled the identification of epitopes with an increased ability to stimulate a class I restricted T cell hybridoma. The Francisella expression library, encompassing the majority of open reading frames of $F$. tularensis 
SchuS4, enabled the identification and characterization of novel targets of cellular immunity. Importantly, the spatially addressed format of both these libraries is a key feature enabling a priori knowledge of the proteins at each location and affords the user flexibility to select individual clones for additional analyses. Furthermore, our studies suggest this methodology can also be modified for discovering antibody reactivities recognized during infection or immunization. In addition, proteins from the Francisella library produced from an expression vector newly constructed for these studies enabled the immunization of mice with defined antigens for the identification of $\mathrm{T}$ cell epitopes. Ultimately, the discovery methodologies we have developed here illustrate the feasibility of screening protein libraries in a high-throughput approach.

\section{Acknowledgments}

This work has been supported in part by funds from the National Institutes of Health contract NO1-AI-40086, R01AI-078345, and NIH/NIAID Southeast Regional Center of Excellence for Emerging Infections and Biodefense (SERCEB) (grant no. U54 AI 057157); M.D.V. was supported by NIAID training grant T32-AI-7362, C.S.A. and D.S. was supported by NIAID training grant T32-AI-07285, and M.D. was supported by NIH/NIAID grant AI-073785.

\section{Abbreviations}

$\begin{array}{ll}\text { APC } & \text { antigen presenting cells } \\ \text { PSA } & \text { prostate specific antigen } \\ \text { MHC } & \text { major histocompatibility complex } \\ \text { T-CAD assay } & \text { T cell antigen discovery assay } \\ \text { THIO } & \text { thioredoxin } \\ \text { DHFR } & \text { dihydrofolate reductase } \\ \text { 6x His } & \text { hexahistidine tag } \\ \text { LVS } & \text { live vaccine strain }\end{array}$

\section{References}

Abdel-Moal UM, et al. Dendritic cell vaccination induces cross-reactive cytotoxic T lymphocytes specific for wild-type and natural variant human immunodeficiency virus type 1 epitopes in HLAA*0201/Kb transgenic mice. Clin Immunol. 2001; 101:51-8. [PubMed: 11580226]

Alexander J, et al. Identification of broad binding class I HLA supertype epitopes to provide universal coverage of influenza A virus. Hum Immunol. 2010; 71:468-74. [PubMed: 20156506]

Altman JD, et al. Phenotypic analysis of antigen-specific T lymphocytes. Science. 1996; 274:94-6. [PubMed: 8810254]

Anderson KS, et al. Intracellular transport of class I MHC molecules in antigen processing mutant cell lines. J Immunol. 1993; 151:3407-19. [PubMed: 8376783]

Andron LA II, Eigelsbach HT. Biochemical and immunological properties of ribonucleic acid-rich extracts from Francisella tularensis. Infect Immun. 1975; 12:137-42. [PubMed: 237834]

Angerman CR, Eisenstein TK. Correlation of the duration and magnitude of protection against Salmonella infection afforded by various vaccines with antibody titers. Infect Immun. 1980; 27:435-43. [PubMed: 6991415]

Anthony DD, Lehmann PV. T-cell epitope mapping using the ELISPOT approach. Methods. 2003; 29:260-9. [PubMed: 12725791]

Aruna BV, et al. A dual altered peptide ligand down-regulates myasthenogenic $\mathrm{T}$ cell responses and reverses experimental autoimmune myasthenia gravis via up-regulation of Fas-FasL-mediated apoptosis. Immunology. 2006; 118:413-24. [PubMed: 16827902] 
Barker JR, Klose KE. Molecular and genetic basis of pathogenesis in Francisella tularensis. Ann N Y Acad Sci. 2007; 1105:138-59. [PubMed: 17395737]

Baron SD, et al. Inactivated Francisella tularensis live vaccine strain protects against respiratory tularemia by intranasal vaccination in an immunoglobulin A-dependent fashion. Infect Immun. 2007; 75:2152-62. [PubMed: 17296747]

Bian H, et al. The use of bioinformatics for identifying class II-restricted T-cell epitopes. Methods. 2003; 29:299-309. [PubMed: 12725795]

Bielekova B, Martin R. Antigen-specific immunomodulation via altered peptide ligands. J Mol Med. 2001; 79:552-65. [PubMed: 11692152]

Buus S, Claesson MH. Identifying multiple tumor-specific epitopes from large-scale screening for overexpressed mRNA. Curr Opin Immunol. 2004; 16:137-42. [PubMed: 15023404]

Chapman AL, et al. Rapid detection of active and latent tuberculosis infection in HIV-positive individuals by enumeration of Mycobacterium tuberculosis-specific T cells. Aids. 2002; 16:228593. [PubMed: 12441800]

Cowley SC, Elkins KL. Multiple T cell subsets control Francisella tularensis LVS intracellular growth without stimulation through macrophage interferon gamma receptors. J Exp Med. 2003; 198:379_ 89. [PubMed: 12885873]

Cowley SC, Elkins KL. Immunity to Francisella. Front Microbiology 2. 2011; 26:1-21.

Davies DH, et al. Antibody profiling by proteome microarray reveals the immunogenicity of the attenuated smallpox vaccine modified vaccinia virus ankara is comparable to that of Dryvax. $\mathrm{J}$ Virol. 2008; 82:652-63. [PubMed: 17977963]

Depla E, et al. Rational design of a multiepitope vaccine encoding T-lymphocyte epitopes for treatment of chronic hepatitis B virus infections. J Virol. 2008; 82:435-50. [PubMed: 17942551]

Dominguez MD, et al. An altered peptide ligand corresponding to a novel epitope from heat-shock protein 60 induces regulatory $\mathrm{T}$ cells and suppresses pathogenic response in an animal model of adjuvant-induced arthritis. Autoimmunity. 2011; 44:461-482.

Doolan DL, et al. Utilization of genomic sequence information to develop malaria vaccines. J Exp Biol. 2003a; 206:3789-802. [PubMed: 14506214]

Doolan DL, et al. Identification of Plasmodium falciparum antigens by antigenic analysis of genomic and proteomic data. Proc Natl Acad Sci U S A. 2003b; 100:9952-7. [PubMed: 12886016]

Eisenstein TK. Evidence for $\mathrm{O}$ antigens as the antigenic determinants in "ribosomal" vaccines prepared from Salmonella. Infect Immun. 1975; 12:364-77. [PubMed: 51007]

Eisenstein TK, Angerman CR. Immunity to experimental Salmonella infection: studies on the protective capacity and immunogenicity of lipopolysaccharide, acetone-killed cells, and ribosomerich extracts of Salmonella typhimurium in C3H/HeJ and CD-1 mice. J Immunol. 1978; 121:1010-4. [PubMed: 690428]

Elkins KL, et al. Innate and adaptive immunity to Francisella. Ann N Y Acad Sci. 2007; 1105:284324. [PubMed: 17468235]

Eyles JE, et al. Protection afforded against aerosol challenge by systemic immunisation with inactivated Francisella tularensis live vaccine strain (LVS). Microb Pathog. 2008; 44:164-8. [PubMed: 17904793]

Fong L, et al. Altered peptide ligand vaccination with Flt3 ligand expanded dendritic cells for tumor immunotherapy. Proc Natl Acad Sci U S A. 2001; 98:8809-14. [PubMed: 11427731]

Gregory RL. Microbial ribosomal vaccines. Rev Infect Dis. 1986; 8:208-17. [PubMed: 3518022]

Gregory SH, et al. Epitope-based vaccination against pneumonic tularemia. Vaccine. 2009; 27:5299306. [PubMed: 19616492]

Gunawardana CG, Diamandis EP. High throughput proteomic strategies for identifying tumourassociated antigens. Cancer Lett. 2007; 249:110-9. [PubMed: 17306453]

He XS, et al. Quantitative analysis of hepatitis C virus-specific CD8(+) T cells in peripheral blood and liver using peptide-MHC tetramers. Proc Natl Acad Sci U S A. 1999; 96:5692-7. [PubMed: 10318946]

Hoops $\mathrm{P}$, et al. Evidence for an extrinsic immunogen in effective ribosomal vaccines from Salmonella typhimurium. Infect Immun. 1976; 13:1184-92. [PubMed: 776831] 
Hunt DF, et al. Characterization of peptides bound to the class I MHC molecule HLA-A2.1 by mass spectrometry. Science. 1992; 255:1261-3. [PubMed: 1546328]

Jia Q, et al. Recombinant attenuated Listeria monocytogenes vaccine expressing Francisella tularensis IglC induces protection in mice against aerosolized Type A F. tularensis. Vaccine. 2009; 27:121629. [PubMed: 19126421]

Johnson W. Ribosomal vaccines. I. Immunogenicity of ribosomal fractions isolated from Salmonella typhimurium and Yersinia pestis. Infect Immun. 1972; 5:947-52. [PubMed: 4564407]

Johnson W. Ribosomal vaccines. II. Specificity of the immune response to ribosomal ribonucleic acid and protein isolated from Salmonella typhimurium. Infect Immun. 1973; 8:395-400. [PubMed: 4199718]

Katsara M, et al. The good, the bad and the ugly: how altered peptide ligands modulate immunity. Expert Opin Biol Ther. 2008; 8:1873-84. [PubMed: 18990075]

Kern F, et al. Measuring Ag-specific immune responses: understanding immunopathogenesis and improving diagnostics in infectious disease, autoimmunity and cancer. Trends Immunol. 2005; 26:477-84. [PubMed: 16039158]

Kessels HW, et al. Circumventing T-cell tolerance to tumour antigens. Biologicals. 2001; 29:277-83. [PubMed: 11851328]

Kessler JH, Melief CJ. Identification of T-cell epitopes for cancer immunotherapy. Leukemia. 2007; 21:1859-74. [PubMed: 17611570]

Kirimanjeswara GS, et al. Prophylactic and therapeutic use of antibodies for protection against respiratory infection with Francisella tularensis. J Immunol. 2007; 179:532-9. [PubMed: 17579074]

Kirimanjeswara GS, et al. Humoral and cell-mediated immunity to the intracellular pathogen Francisella tularensis. Immunol Rev. 2008; 225:244-55. [PubMed: 18837786]

Kita E, Kashiba S. Immunogenicity of transfer RNA isolated from a two-heptose rough mutant of Salmonella typhimurium LT2 in mouse typhoid infection. Immunology. 1983; 50:369-76. [PubMed: 6195095]

Kita E, et al. Immunogenic dialyzable factor derived from a ribosomal fraction of Salmonella typhimurium. I. Preparation of the protective dialyzable factor from the ribosomal fraction by the freeze-thaw procedure. Microbiol Immunol. 1983a; 27:7-24. [PubMed: 6346023]

Kita E, et al. Immunogenic dialyzable factor derived from a ribosomal fraction of Salmonella typhimurium. II. Isolation and characterization of the protective moiety in the dialyzable factor. Microbiol Immunol. 1983b; 27:117-30. [PubMed: 6346025]

Klenerman $\mathrm{P}$, et al. The effects of natural altered peptide ligands on the whole blood cytotoxic $\mathrm{T}$ lymphocyte response to human immunodeficiency virus. Eur J Immunol. 1995; 25:1927-31. [PubMed: 7542596]

Koelle DM. Expression cloning for the discovery of viral antigens and epitopes recognized by T cells. Methods. 2003; 29:213-26. [PubMed: 12725787]

Lee PP, et al. Characterization of circulating T cells specific for tumor-associated antigens in melanoma patients. Nat Med. 1999; 5:677-85. [PubMed: 10371507]

Lemmel C, Stevanovic S. The use of HPLC-MS in T-cell epitope identification. Methods. 2003; 29:248-59. [PubMed: 12725790]

Martin W, et al. Bioinformatics tools for identifying class I-restricted epitopes. Methods. 2003; 29:289-98. [PubMed: 12725794]

McGavern DB, et al. Molecular anatomy of antigen-specific CD8(+) T cell engagement and synapse formation in vivo. Nat Immunol. 2002; 3:918-25. [PubMed: 12352968]

McSorley SJ, et al. Tracking salmonella-specific CD4 T cells in vivo reveals a local mucosal response to a disseminated infection. Immunity. 2002; 16:365-77. [PubMed: 11911822]

Mesri EA, et al. Major Trypanosoma cruzi antigenic determinant in Chagas' heart disease shares homology with the systemic lupus erythematosus ribosomal P protein epitope. J Clin Microbiol. 1990; 28:1219-24. [PubMed: 1696282]

Misfeldt ML, Johnson W. Variability of protection in inbred mice induced by a ribosomal vaccine prepared from Salmonella typhimurium. Infect Immun. 1976; 14:652-9. [PubMed: 786889] 
Misfeldt ML, Johnson W. Role of endotoxin contamination in ribiosomal vaccines prepared from Salmonella typhimurium. Infect Immun. 1977; 17:98-104. [PubMed: 328399]

Misfeldt ML, Johnson W. Protective ability of Salmonella ribosomal protein and RNA in inbred mice. Infect Immun. 1978; 21:286-91. [PubMed: 30697]

Misfeldt ML, Johnson W. Identification of protective cell surface proteins in ribosomal fractions from Salmonella typhimurium. Infect Immun. 1979; 24:808-16. [PubMed: 381202]

Moise L, et al. In silico-accelerated identification of conserved and immunogenic variola/vaccinia Tcell epitopes. Vaccine. 2009; 27:6471-9. [PubMed: 19559119]

Nano FE, Schmerk C. The Francisella pathogenicity island. Ann N Y Acad Sci. 2007; 1105:122-37. [PubMed: 17395722]

Ogg GS, et al. Quantitation of HIV-1-specific cytotoxic T lymphocytes and plasma load of viral RNA. Science. 1998; 279:2103-6. [PubMed: 9516110]

Overwijk WW, et al. gp100/pmel 17 is a murine tumor rejection antigen: induction of "self"-reactive, tumoricidal T cells using high-affinity, altered peptide ligand. J Exp Med. 1998; 188:277-86. [PubMed: 9670040]

Peters B, et al. The immune epitope database and analysis resource: from vision to blueprint. PLoS Biol. 2005; 3:e91. [PubMed: 15760272]

Pogue RR, et al. Amino-terminal alteration of the HLA-A*0201-restricted human immunodeficiency virus pol peptide increases complex stability and in vitro immunogenicity. Proc Natl Acad Sci U S A. 1995; 92:8166-70. [PubMed: 7545295]

Probst $\mathrm{P}$, et al. Identification and characterization of $\mathrm{T}$ cell-stimulating antigens from Leishmania by CD4 T cell expression cloning. J Immunol. 2001; 166:498-505. [PubMed: 11123329]

Rawool DB, et al. Utilization of Fc receptors as a mucosal vaccine strategy against an intracellular bacterium, Francisella tularensis. J Immunol. 2008; 180:5548-57. [PubMed: 18390739]

Richards KA, et al. Cutting edge: CD4 T cells generated from encounter with seasonal influenza viruses and vaccines have broad protein specificity and can directly recognize naturally generated epitopes derived from the live pandemic H1N1 virus. J Immunol. 2010; 185:4998-5002. [PubMed: 20889549]

Rivoltini L, et al. Induction of tumor-reactive CTL from peripheral blood and tumor-infiltrating lymphocytes of melanoma patients by in vitro stimulation with an immunodominant peptide of the human melanoma antigen MART-1. J Immunol. 1995; 154:2257-65. [PubMed: 7868898]

Sadegh-Nasseri S, et al. Suboptimal engagement of the T-cell receptor by a variety of peptide-MHC ligands triggers T-cell anergy. Immunology. 2010; 129:1-7. [PubMed: 20002785]

Sanderson S, Shastri N. LacZ inducible, antigen/MHC-specific T cell hybrids. Int Immunol. 1994; 6:369-76. [PubMed: 8186188]

Slansky JE, et al. Enhanced antigen-specific antitumor immunity with altered peptide ligands that stabilize the MHC-peptide-TCR complex. Immunity. 2000; 13:529-38. [PubMed: 11070171]

Sospedra M, et al. Use of combinatorial peptide libraries for T-cell epitope mapping. Methods. 2003; 29:236-47. [PubMed: 12725789]

Stetson DB, et al. Rapid expansion and IL-4 expression by Leishmania-specific naive helper T cells in vivo. Immunity. 2002; 17:191-200. [PubMed: 12196290]

Tsukamoto H, et al. TCR ligand avidity determines the mode of B-Raf/Raf-1/ERK activation leading to the activation of human CD4+ T cell clone. Eur J Immunol. 2006; 36:1926-37. [PubMed: 16791876]

Turner MJ, et al. T-cell antigen discovery (T-CAD) assay: a novel technique for identifying T cell epitopes. J Immunol Methods. 2001; 256:107-19. [PubMed: 11516759]

Uhlin M, et al. Is the activity of partially agonistic MHC:peptide ligands dependent on the quality of immunological help? Scand J Immunol. 2006; 64:581-7. [PubMed: 17083613]

Valentino M, Frelinger J. An approach to the identification of T cell epitopes in the genomic era: application to Francisella tularensis. Immunol Res. 2009; 45:218-228.

Valentino MD, et al. Identification of a dominant CD4 T cell epitope in the membrane lipoprotein Tul4 from Francisella tularensis LVS. Mol Immunol. 2009; 46:1830-8. [PubMed: 19233475] 
Valentino MD, et al. Identification of T-cell epitopes in Francisella tularensis using an ordered protein array of serological targets. Immunology. 2011; 132:348-60. [PubMed: 21214540]

Venneman MR, Bigley NJ. Isolation and partial characterization of an immunogenic moiety obtained from Salmonella typhimurium. J Bacteriol. 1969; 100:140-8. [PubMed: 4898982]

Vita R, et al. The curation guidelines of the immune epitope database and analysis resource. Cytometry A. 2008; 73:1066-70. [PubMed: 18688821]

Vita R, et al. The immune epitope database 2.0. Nucleic Acids Res. 2010; 38:D854-62. [PubMed: 19906713]

Walsh SR, et al. Diverse recognition of conserved orthopoxvirus CD8+ T cell epitopes in vaccinated rhesus macaques. Vaccine. 2009; 27:4990-5000. [PubMed: 19531389]

Wang R, et al. The stimulation of low-affinity, nontolerized clones by heteroclitic antigen analogues causes the breaking of tolerance established to an immunodominant T cell epitope. J Exp Med. 1999; 190:983-94. [PubMed: 10510088]

Wang RF. Identification of MHC class II-restricted tumor antigens recognized by CD4+ T cells. Methods. 2003; 29:227-35. [PubMed: 12725788]

Wehrly TD, et al. Intracellular biology and virulence determinants of Francisella tularensis revealed by transcriptional profiling inside macrophages. Cell Microbiol. 2009; 11:1128-50. [PubMed: 19388904]

Woolard MD, et al. Francisella tularensis-infected macrophages release prostaglandin E2 that blocks T cell proliferation and promotes a Th2-like response. J Immunol. 2007; 178:2065-74. [PubMed: 17277110]

Youmans AS, Youmans GP. Further Studies on a Labile Immunogenic Particulate Substance Isolated from Mycobacterium Tuberculosis. J Bacteriol. 1964a; 87:278-85. [PubMed: 14151045]

Youmans AS, Youmans GP. Nature of the Labile Immunogenic Substance in the Particulate Fraction Isolated from Mycobacterium Tuberculosis. J Bacteriol. 1964b; 88:1030-7. [PubMed: 14219015]

Youmans AS, Youmans GP. Immunogenic mycobacterial ribosomal and ribonucleic Acid preparations: chemical and physical characteristics. Infect Immun. 1970; 2:659-68. [PubMed: 16557892]

$\mathrm{Yu}$ P, et al. Fetal exposure to high-avidity TCR ligand enhances expansion of peripheral T regulatory cells. J Immunol. 2008; 181:73-80. [PubMed: 18566371] 


\section{Highlights}

- We have developed a method to identify T cell epitopes, which are critical tools for many modern immunologic studies

- The method utilizes bacterial expression libraries and solid-phase antigen delivery, which we demonstrate is suitable for screening thousands of clones

- The method was used to identify altered peptide MHC class I restricted epitopes with super-agonist activities

- We showed the feasibility of screening an extensive expression library constructed from Francisella tularensis

- A new expression vector was constructed for immunization and used to identify $\mathrm{T}$ cell epitopes in Francisella pathogenicity island encoded proteins 
A

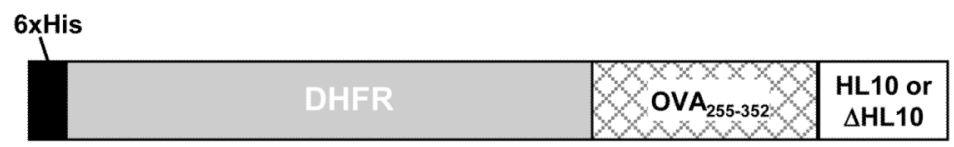

B

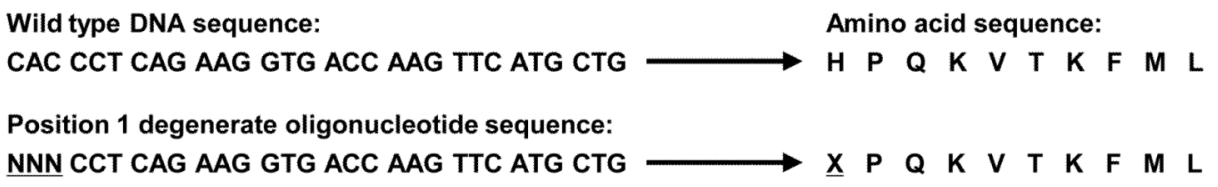

C

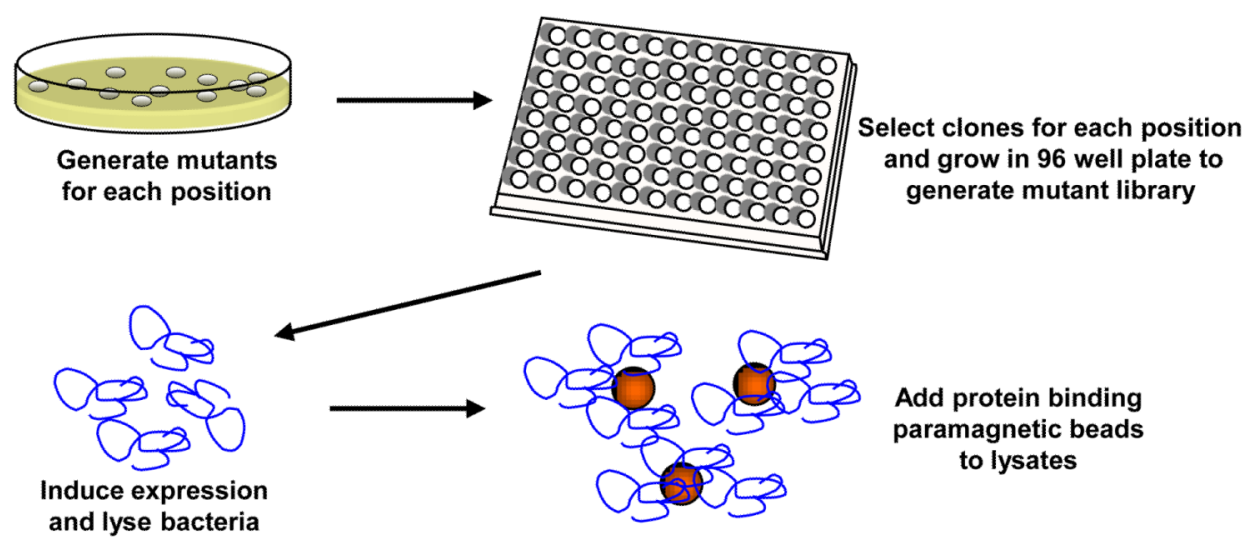

Figure 1. Scheme to identify enhanced peptide ligands of PSA epitope, HL10

A) Mutations were introduced into the HL10 epitope using degenerate oligonucleotides, which when expressed result in random amino acid substitutions. $\mathrm{N}$ represents any one of 4 bases; $\mathrm{X}$ represents any given amino acid codon. A library was generated for each position of the peptide epitope. B) Illustration of the oligonucleotides corresponding to the epitope region used to generate altered peptide ligand (APL) sequences. C) Sequences encoding APL products were cloned into the pQE40 vector and transformed en mass into E. coli. Ninety individual colonies were picked and arrayed into wells of a 96 well plate. This procedure was conducted for each position within the sequence of the HL10 epitope to generate the ten individual positional mutant libraries. The bacterial clones were subsequently expressed, lysed in individual wells of 96 well plate, and individually coupled to tosyl-activated magnetic beads that were then used as a source of antigen in the functional assay. 

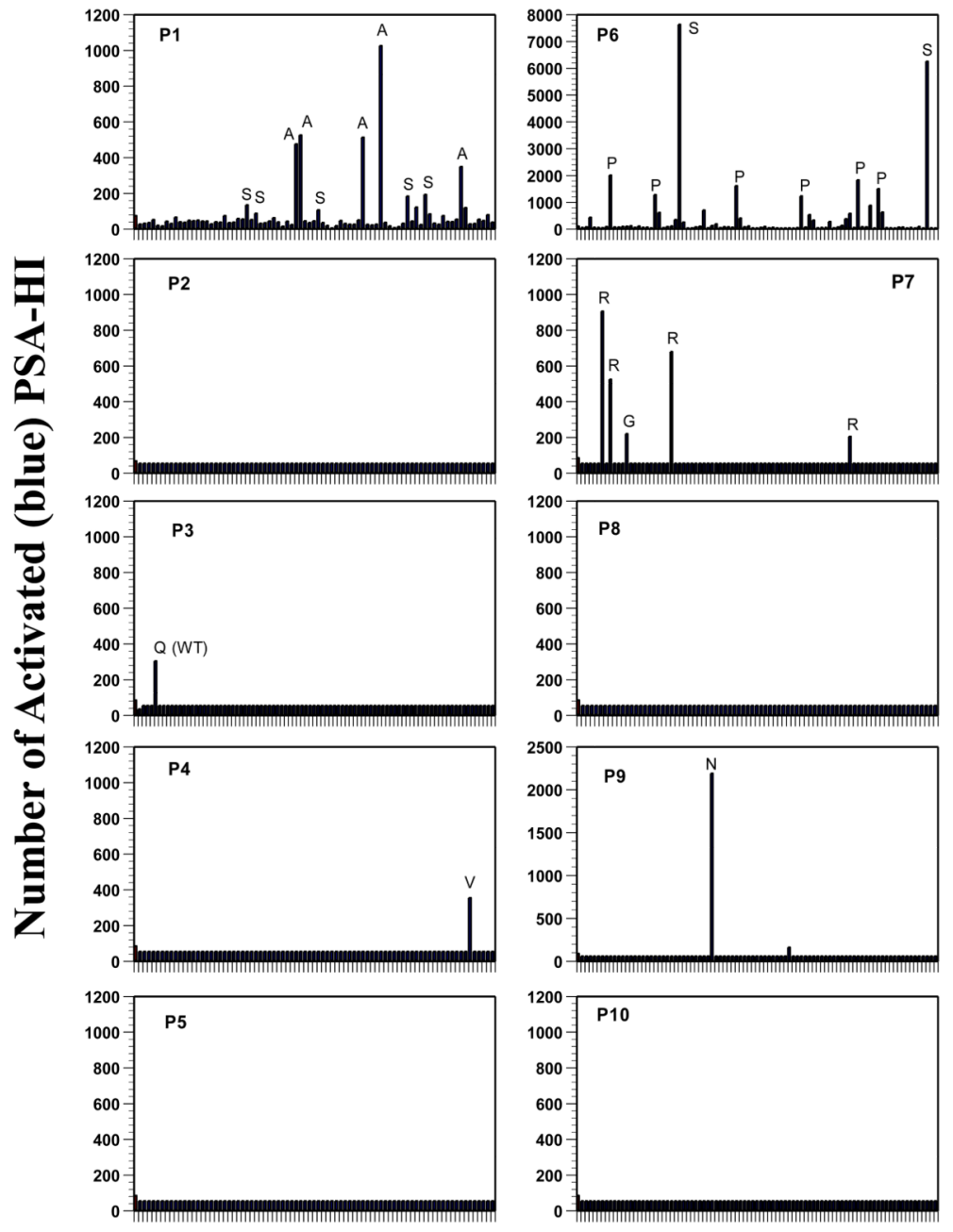

Figure 2. HL10 mutant library screens

Each clone of the 10 mutant libraries encoding variants of the HL10 epitope was screened individually. Approximately 90 mutant clones were screened from each library. The library designation is indicated in the upper left-hand corner of each panel, with the numbers indicating the position of the amino acid in the peptide epitope. Individual wells (A1, A2, A3...H12) of a 96 well plate are indicated by the marks on the horizontal axis of each panel and each well contains lysate from a single clone. After washing, beads that had been coupled with protein were added to cultures containing $2 \times 10^{5}$ PSA-H1 and $1 \times 10^{5}$ cells of RAW, a H2L ${ }^{\mathrm{d}}$ expressing macrophage cell line. After 12 hours at $37^{\circ} \mathrm{C}$ wells were developed with X-Gal and scored for the number of $\beta$-galactosidase expressing hybridomas. PSA-HI hybridoma reactivity against the wild type HL10 epitope is shown in the first well of each panel. Altered peptide ligands that exhibit super agonist activity are identified as having higher levels of activation compared to the wild type sequence found in the first well. Letters above the lines within the panel indicate the amino acid substitution in the peptide. 


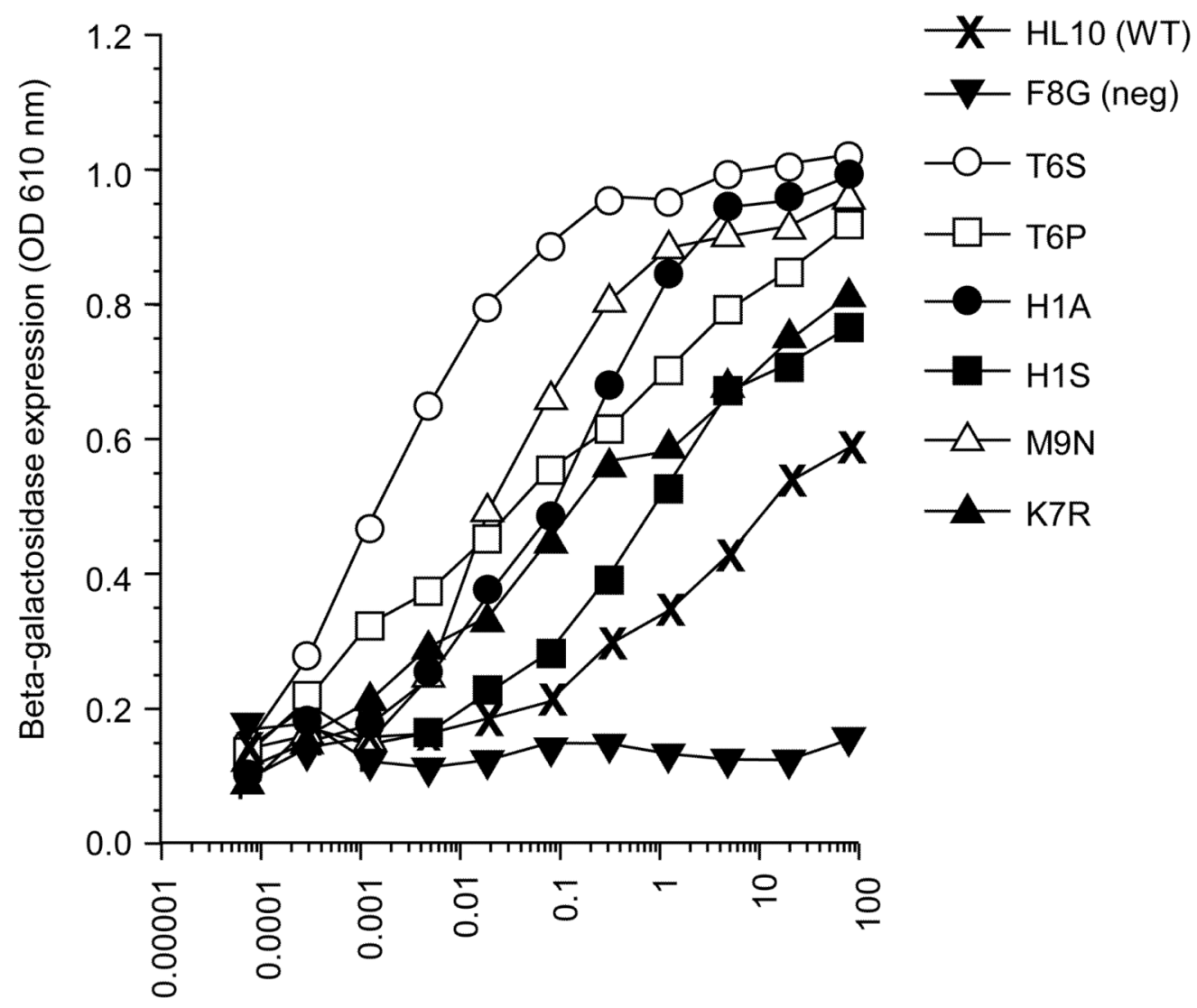

[peptide] uM

Figure 3. Activity of mutant synthetic peptides on the activation of PSA-HI

Synthetic peptides corresponding to the altered peptide ligands identified in the library screens were tested for activity using the HL10 specific hybridoma PSA-HI. Decreasing concentrations of peptides were added to $1 \times 10^{5}$ PSA-HI and $1 \times 10^{5}$ cells of RAW.

Cultures were incubated overnight at $37^{\circ} \mathrm{C}$. $\beta$-galactosidase expression was measured using CPRG. Peptides are denoted as follows: (X) HL10 (WT), ( $)$ F8G (a negative control), (o)

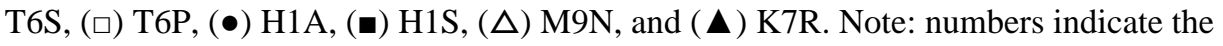
position of mutation in the peptide (e.g. T6S is a threonine to serine substitution at position 6 in the peptide). 


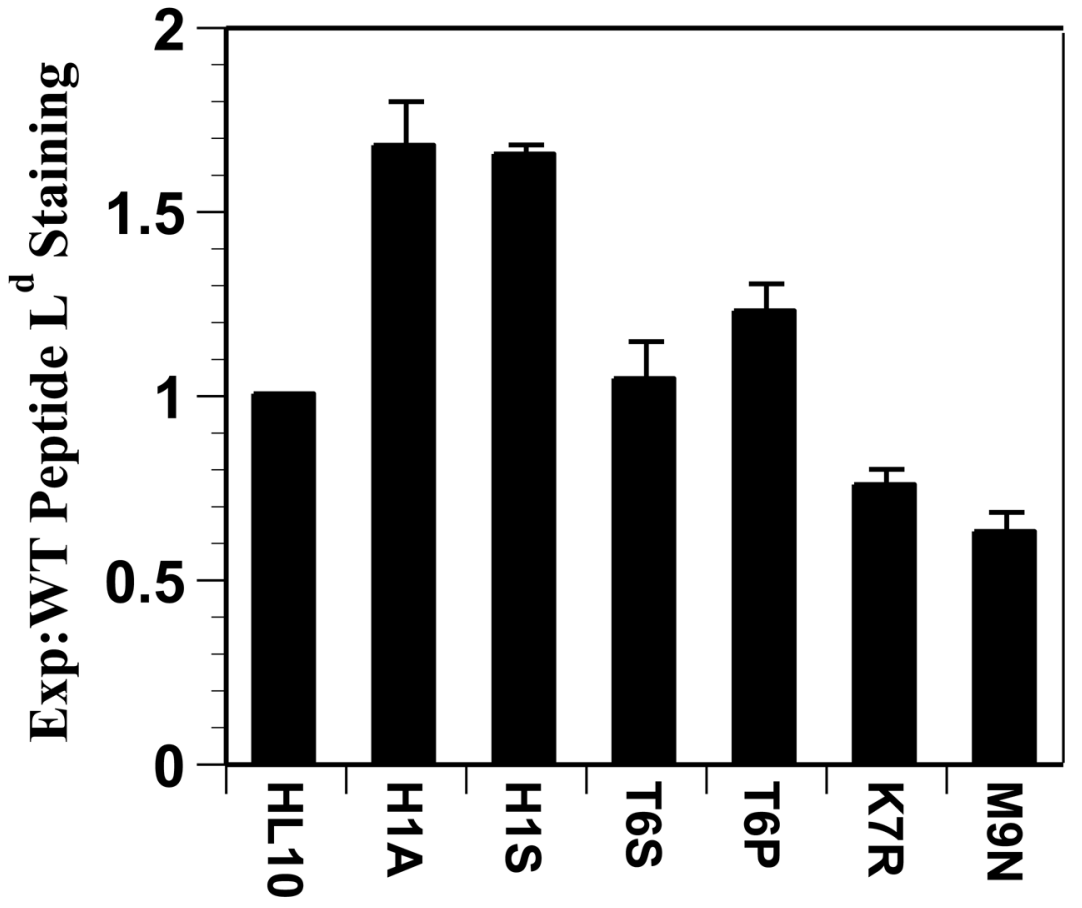

Figure 4. T-2 stabilization assays using the altered peptide ligands

Peptide stabilization of empty $\mathrm{H}_{2} \mathrm{~L}^{\mathrm{d}}$ was assessed using $\mathrm{T} 2-\mathrm{L}^{\mathrm{d}}$ cells, as described in materials and methods section 2.2. Briefly, the cell line T2- $\mathrm{L}^{\mathrm{d}}$ expresses low levels of unstable surface H2L ${ }^{d}$ on its surface \{Anderson, $1993 \# 602$ \}, which can be stabilized by pulsing the cells with peptide that binds the $\mathrm{H} 2 \mathrm{~L}^{\mathrm{d}}$ molecule. $\mathrm{T} 2-\mathrm{L}^{\mathrm{d}}$ cells were incubated with the altered HL10 epitope peptides shown for 16 hours, and were assayed for surface stabilized $\mathrm{H} 2 \mathrm{~L}^{\mathrm{d}}$, detected using the anti- $\mathrm{L}^{\mathrm{d}}$ antibody clone $30-5-7 \mathrm{~S}$. Cells were secondary stained with goat-anti-mouse FITC and analyzed by flow cytometry. Peptide loading is reported as the ratio of mean channel fluorescence of mutant and control peptides divided by the mean channel fluorescence of HL10, after the subtraction of background staining from each. 
A

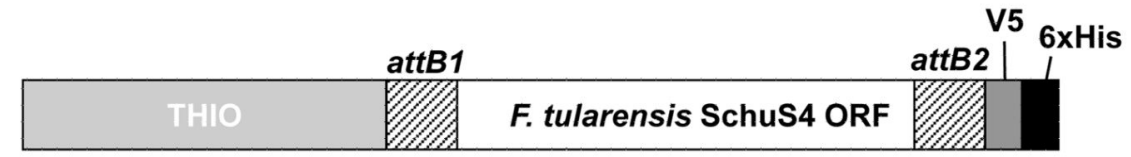

B
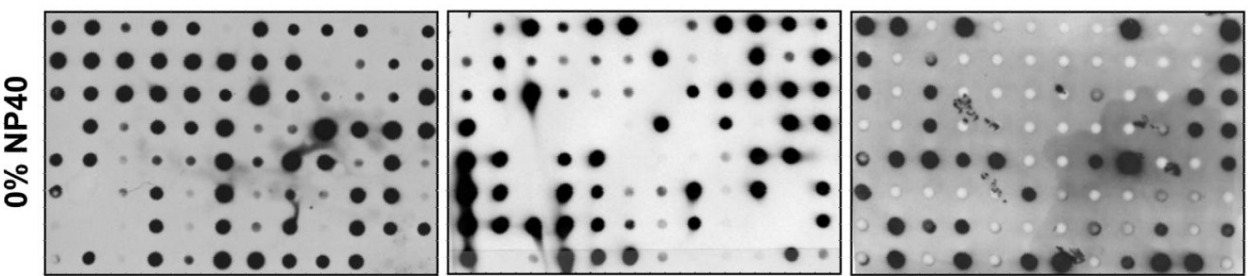

C
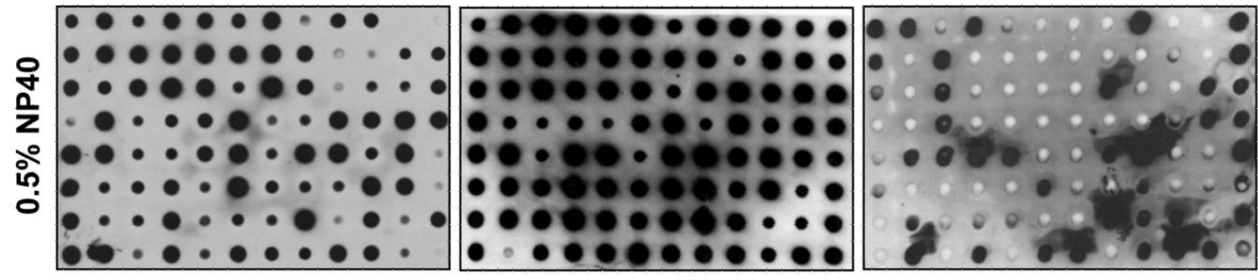

Figure 5. Verification of protein expression from the Francisella expression library A) Illustration of the fusion protein produced by the Gateway pBAD-DEST49 vector. The individual Francisella ORFs were recombined into pBAD-DEST49 vector in frame to attach the bacterial protein thioredoxin (THIO) and V5 and 6x His tags. Protein sequence resulting from the recombination sites is denoted as attB1/attB2. Expression clones containing Francisella ORFs were lysed either without (B) or with addition of $0.5 \%$ NP-40 (C) detergent to the lysis buffer, prior to purification over Ni-NTA chromatography. B \& C) Protein expression and purification was verified by blotting an aliquot of each protein onto nitrocellulose using a BioRad dot blot apparatus and probing with anti-thioredoxin antibody followed by detection with anti-mouse IgG-HRP. A dot blot for each library expression plate (twenty 96 well plates in total) was conducted. Dot blots of library plates representative of ORFs ranging 43-163 aa (left), 163-362 (middle), and 362-1171 aa (right) that encompass a range of sizes of Francisella ORFs are shown. The inclusion of $0.5 \%$ NP-40 detergent to the lysis buffer was shown to substantially increase the purification yield, the same selection of plates are shown for both conditions and were processed identically. 

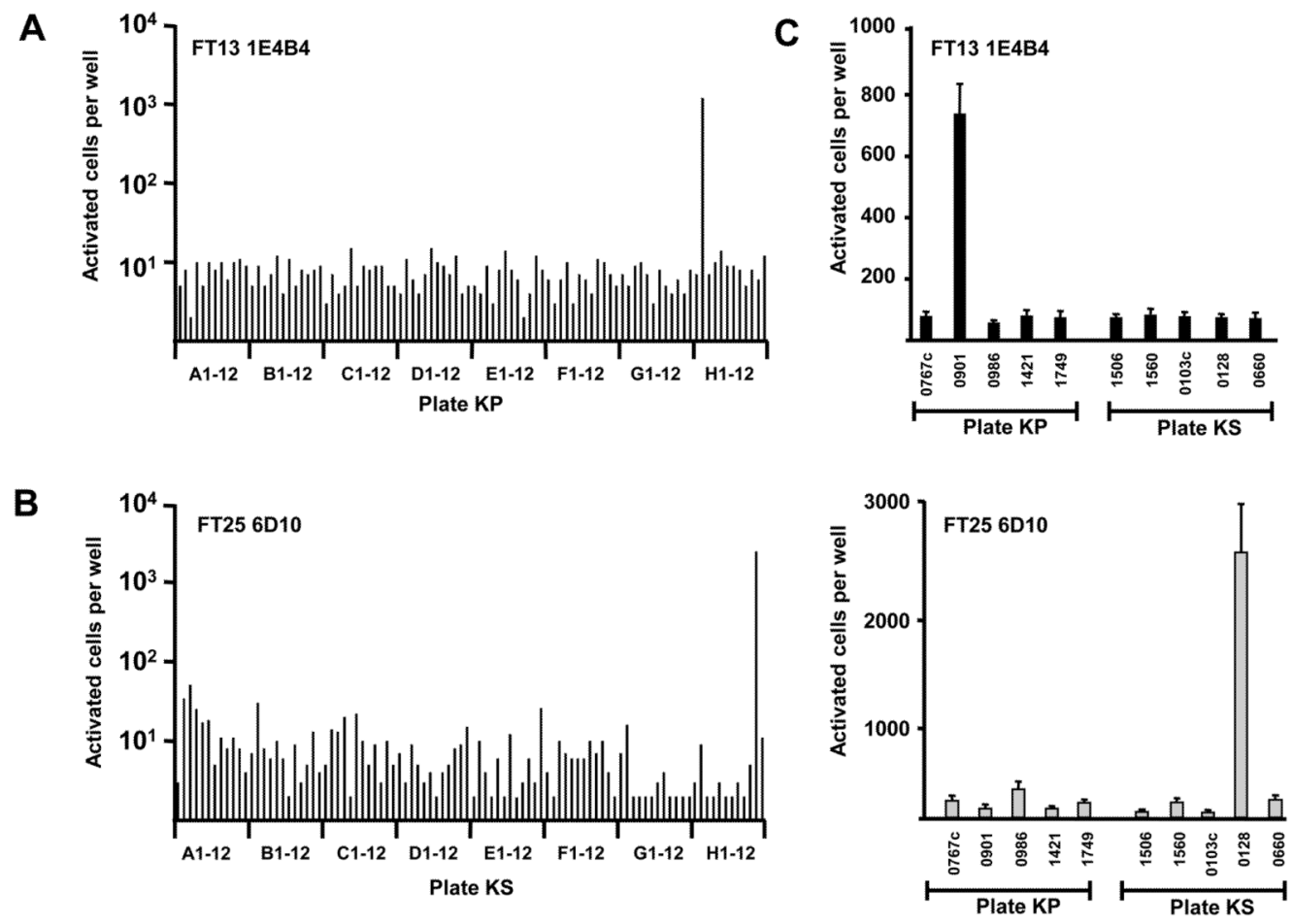

Figure 6. Illustration of the protein library screening approach

A \& B) Purified protein from each expression library plate were screened against Francisella specific hybridomas in a functional assay and activated cells were identified and enumerated by X-Gal. A) The Tul4 specific hybridoma FT13 1E4B4 showed reactivity to only one well when screened against the library plate KP containing its cognate antigen (well H2) and 95 other Francisella proteins, which serve as negative controls. B) The FT25 6D10 hybridoma of unknown specificity, shows reactivity to an antigen in the library plate KS (well H11), while no reactivity was seen against the other 95 proteins. C) A subset of five proteins from plates KS and KP, including the antigens recognized by the two hybridomas, were re-arrayed to include replicates and were screened in functional assays against the FT13 1E4B4 and FT25 6D10 hybridomas. The proteins are denoted by their FTT designation number (eg. 0767c $=$ FTT0767c). The control FT14 1E4B4 hybridoma was specifically activated by FTT0128 (Tul4) located in plate KP, whereas, the FT25 6D10 hybridoma was activated by FTT0128 (L3) located in plate KS. Error bars represent standard deviation from the mean. Representative reactivity patterns from two experiments are shown. 
A

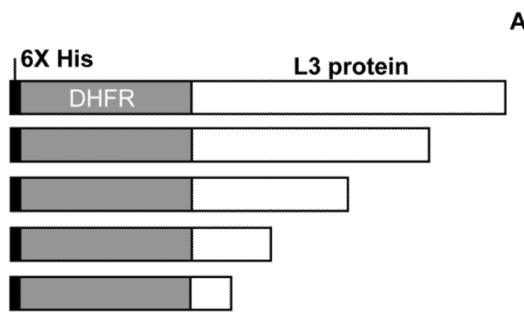

Amino Acids

of L3

149

118

68

35

18
B
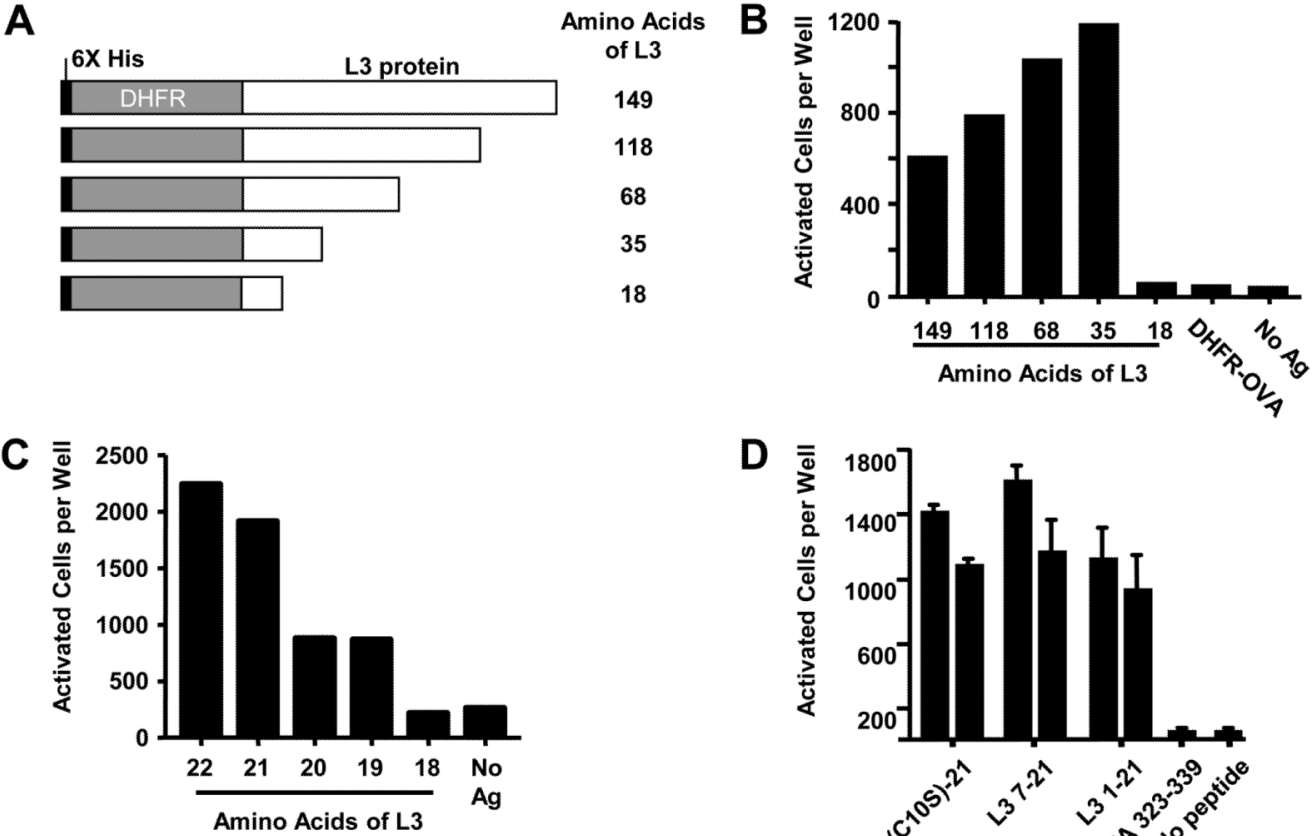

D

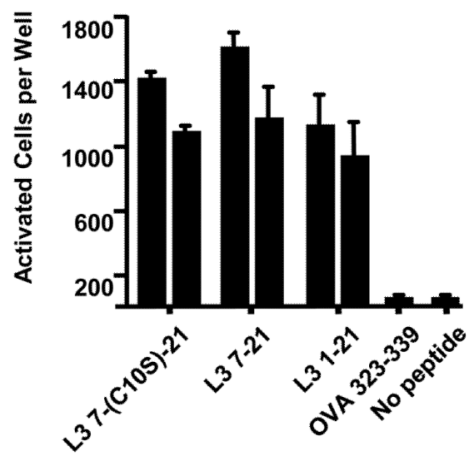

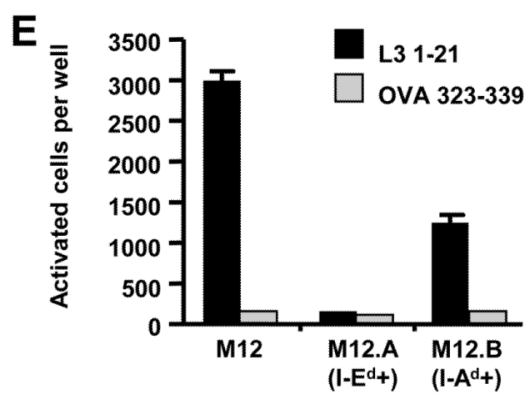

Figure 7. Mapping and validating the epitope reactivity of the FT25 6 D10 hybridoma Hybridomas were incubated with splenocytes and deletion proteins conjugated to tosylactivated beads. A) Illustration of full length L3 and the four carboxy-terminal deletion constructs in the pQE40 bacterial expression vector, the black box indicates $6 \mathrm{x}$ His tag, the gray box indicates murine DHFR protein, and the open box denotes the portions of L3 protein fused in frame with DHFR. B) The constructs shown in (A) were used for initial mapping experiments. C) Fine mapping experiments indicate the hybridoma recognized an epitope within the first 21 amino acids of L3. D) Synthesized peptides were used to validate the hybridoma recognized an epitope within residues 7-21 of L3. E) The M12 B cell line expressing only either $\mathrm{I}-\mathrm{E}^{\mathrm{d}}$ or I-A $\mathrm{A}^{\mathrm{d}}$ indicated that the hybridoma recognizes the L3 1-21 peptide displayed by the $\mathrm{I}-\mathrm{A}^{\mathrm{d}}$ restriction element. 
A

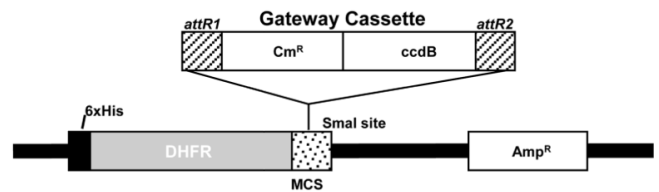

B

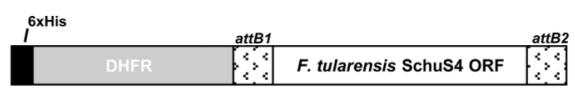

C

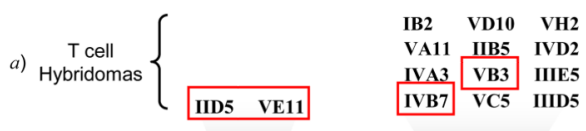

IgIC:

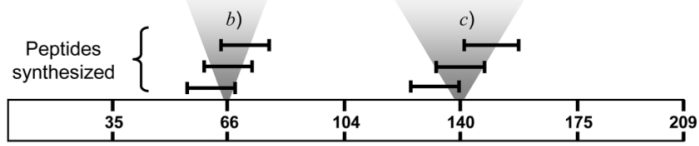

D
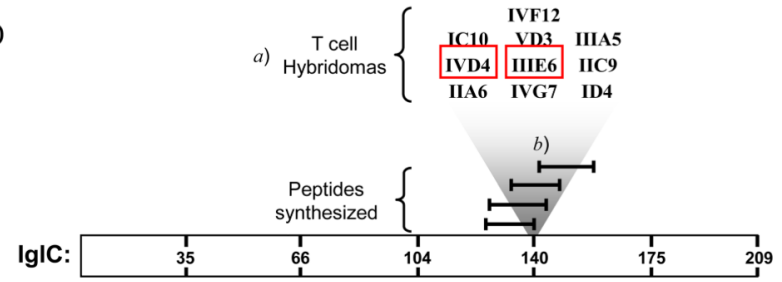

E

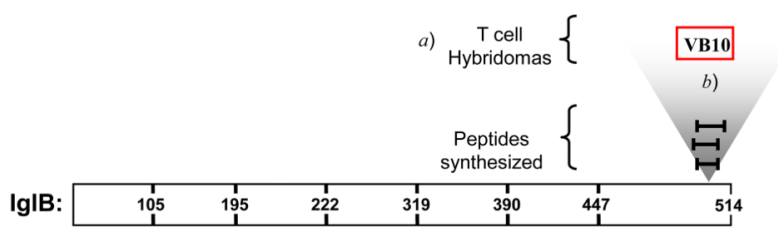

Figure 8. A new Gateway vector was utilized to generate IglC and IglB specific hybridomas for epitope mapping studies

A) A schematic of the newly constructed destination vector pQE40-DEST. The Gateway cassette was inserted into the multiple cloning site of pQE40 vector to generate the pQE40DEST vector. Chloramphenicol resistance gene $\left(\mathrm{Cm}^{\mathrm{R}}\right), \mathrm{ccdB}$ suicide gene $(\mathrm{ccdB})$, and recombination sites (attR1/attR2) are denoted. B) Illustration of the fusion protein containing a Francisella ORF expressed by the pQE40-DEST vector. C \& D) Summary of IglC hybridoma reactivity in C57BL/6 (C) and BALB/c (D) mice. E) Summary of IglB hybridoma reactivity in $\mathrm{C} 57 \mathrm{BL} / 6$ mice. The individual carboxy-terminal truncation deletion constructs for each protein are indicated by amino acid numbers within each protein. Protein specific hybridomas are indicated (a) above their respective reactivity regions (b, c) which were determined using the deletion constructs. T cell hybridomas that were utilized for further validation with peptides are denoted with boxes. The peptides that were subsequently synthesized are also shown and indicated by black bars. 

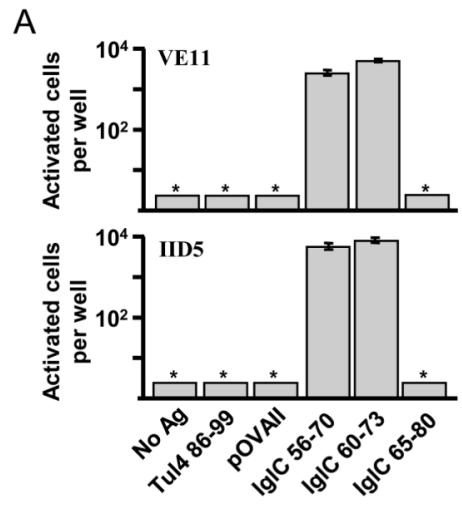

$\mathrm{B}$

C

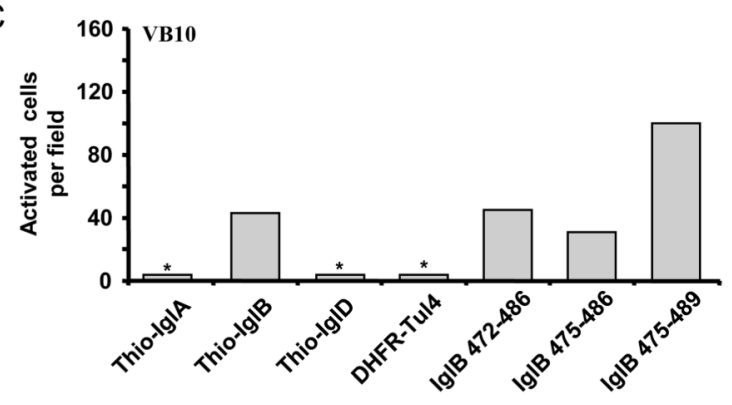

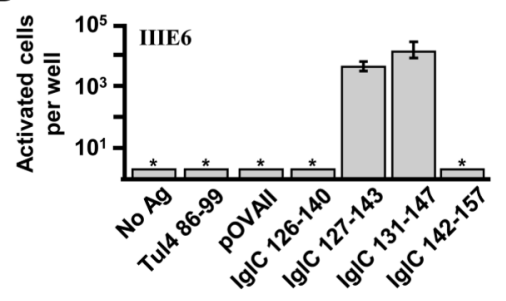
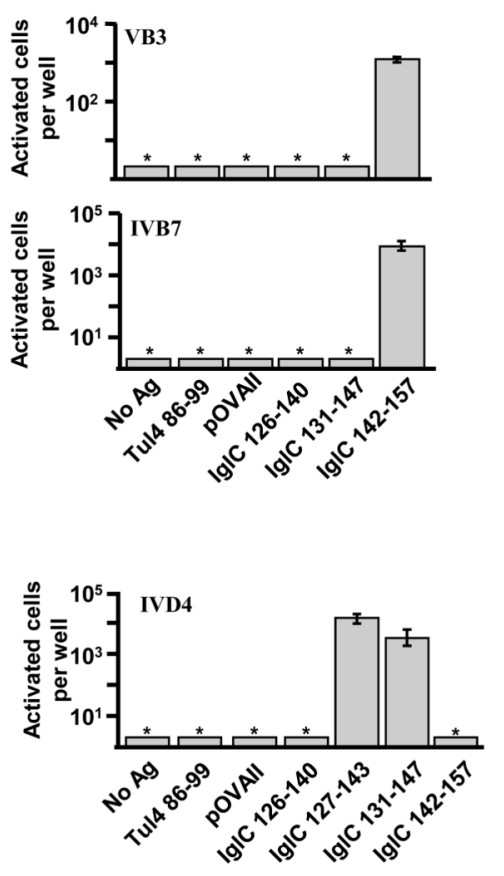

Figure 9. Validation of IglC and IglB epitopes using synthetic peptides

A) The IglC specific hybridomas from C57BL/6 mice recognized two different epitope regions within IglC and were activated by peptides $56-70$ and $60-73$ or $142-157$. B) The $\mathrm{IglC}$ specific hybridomas from $\mathrm{BALB} / \mathrm{c}$ mice recognized a single epitope region within IglC and were activated by peptides 127-143 and 131-143. C) The IglB specific hybridoma from C57BL/6 mice recognizes a single epitope region within IglB and was activated by the overlapping peptides 472-486, 475-486, and 475-489. 


\section{Table 1}

Summary of epitopes identified by recombinant protein immunization of selected Francisella ORFs expressed in the pQE40-DEST vector

\begin{tabular}{|c|c|c|c|}
\hline Protein & Mouse strain & AA residues & Epitope sequence \\
\hline IglB & C57BL/6 & $475-489$ & KPGWYSCKINVIPHI \\
\hline \multirow{2}{*}{ IglC } & \multirow{3}{*}{ C57BL/6 } & $56-70$ & GEDVTKADSATAAAS \\
\cline { 3 - 4 } & & $60-73$ & TKADSATAAASVIR \\
\cline { 3 - 4 } & & $142-157$ & SNLELYPISAKAFSISI \\
\hline \multirow{2}{*}{ IglC } & \multirow{2}{*}{ BALB/C } & $127-143$ & QEYKTDEAWGIMIDLSN \\
\cline { 3 - 4 } & & $131-147$ & DEAWGIMIDLSNLELY \\
\hline
\end{tabular}

